\title{
Flora polínica da Reserva do Parque Estadual das Fontes do Ipiranga (São Paulo, Brasil)
}

\author{
Família: 107-Euphorbiaceae s.l. \\ Angela Maria da Silva Corrêa ${ }^{1,2}$, Maria Amélia Vitorino da Cruz Barros ${ }^{1}$, Maria Stella Fernandes Silvestre- \\ Capelato $^{1}$, Michel Aprigio Pregun ${ }^{1}$, Priscila Gardino Raso ${ }^{1}$ e Inês Cordeiro ${ }^{1}$
}

Recebido: 17.09.2009; aceito: 21.01.2010

\begin{abstract}
Pollen flora of "Reserva do Parque Estadual das Fontes do Ipiranga" (São Paulo, Brasil). Family: 107-Euphorbiaceae s.l.). Pollen grains morphology of 14 genera and 27 species of Euphorbiaceae (Actinostemon klotzschii (Didr.) Pax, Alchornea sidifolia Müll. Arg., A. triplinervia (Spreng.) Müll. Arg., Croton floribundus Spreng., C. fuscescens Spreng., C. glandulosus L., C. lundianus ( Didr.) Müll. Arg., C. organensis Baill., C. salutaris Casar., C. vulnerarius Baill., Dalechampia triphylla Lam., Euphorbia heterophylla L., E. hirta L., E. hyssopifolia L., E. peplus L., Gonatogyne brasiliensis Müll. Arg., Hieronyma alchorneoides Allemão, Maprounea guianensis Aubl., Pera obovata (Klotzsch) Baill., Phyllanthus caroliniensis Walt., P. niruri L., P. tenellus Roxb., Plukenetia serrata (Vell.) L.J. Gillespie, Sapium glandulosum (L.) Morong, Savia dictyocarpa Müll. Arg., Sebastiania klotzschiana (Müll. Arg.) Müll. Arg. and S. serrata (Baill.) Müll. Arg., ocurring in the "Reserva do Parque Estadual das Fontes do Ipiranga" was studied. Descriptions, illustrations, and additional observations are presented for all species studied, as well as keys for some taxa only.
\end{abstract}

Key words: Euphorbiaceae s.l., pollen flora, pollen grain

RESUMO - (Flora polínica da Reserva do Parque Estadual das Fontes do Ipiranga (São Paulo, Brasil). Família 107-Euphorbiaceae s.l.). Foram estudados os grãos de pólen de 14 gêneros e 27 espécies de Euphorbiaceae s.l., ocorrentes na "Reserva do Parque Estadual da Fontes do Ipiranga: Actinostemon klotzschii (Didr.) Pax, Alchornea sidifolia Müll. Arg., A. triplinervia (Spreng.) Müll. Arg., Croton floribundus Spreng., C. fuscescens Spreng., C. glandulosus L., C. lundianus (Didr.) Müll. Arg., C. organensis Baill., C. salutaris Casar., C. vulnerarius Baill., Dalechampia triphylla Lam., Euphorbia heterophylla L., E. hirta (L.) Millsp., E. hyssopifolia (L.) Small, E. peplus L., Gonatogyne brasiliensis Müll. Arg., Hieronyma alchorneoides Allemão, Maprounea guianensis Aubl., Pera obovata (Klotzsch) Baill., Phyllanthus caroliniensis Walt., $P$. niruri L., P. tenellus Roxb., Plukenetia serrata (Vell.) L.J. Gillespie, Sapium glandulosum (L.) Morong, Savia dictyocarpa Müll. Arg., Sebastiania klotzschiana (Müll. Arg.) Müll. Arg., S. serrata (Baill.) Müll. Arg. Para todos os táxons estudados, são apresentadas descrições, ilustrações, e observações adicionais, bem como chaves polínicas para a identificação das espécies de alguns gêneros.

Palavras-chave: flora polínica, Euphorbiaceae s.l., grãos de pólen.

\section{Introdução}

O presente trabalho faz parte do projeto elaborado por Melhem et al. (1984), que visa caracterizar morfologicamente os grãos de pólen das famílias ocorrentes na Reserva do Parque Estadual das Fontes do Ipiranga (PEFI), com o objetivo de complementar os levantamentos taxonômicos realizados na mesma área segundo planejamento apresentado por Melhem et al. (1981) e finalizado em Nakajima et al. (2001). O formato atual segue Cruz-Barros \& Souza (2005).
Segundo Cordeiro (1989), a família Euphorbiaceae está representada na Reserva por 16 gêneros e 28 espécies: Actinostemon Mart. ex Klotzsch (Actinostemon klotzschii (Didrichs) Pax), Alchornea O. Swartz (Alchornea sidifolia Müll. Arg., A. triplinervia (Spreng.) Müll. Arg.), Chamaesyce S.F. Gray (C. hirta (L.) Millsp., C. hyssopifolia (L.) Small), Croton L. (C. floribundus Spreng., $C$. fuscescens Spreng., C. glandulosus L., C. lundianus (F. Diedrichs) Müll. Arg., C. organensis Baill., $C$. salutaris Casar., C. vulnerarius Baill.), Dalechampia

1. Instituto de Botânica, Caixa Posta 3005, 01061-970 São Paulo, SP, Brasil

2. Autor para correspondência: angelamsc2000@yahoo.com.br 
L. (D. triphylla Lam.), Euphorbia L. (E. heterophylla L., E. peplus (L.) Millsp.), Fragariopsis St. Hil. (F. scandens St. Hil.), Hyeronima Allemão ( $H$. alchorneoides Allemão), Maprounea Aubl. (M. guianensis Aubl.), Pera Mutis (P. obovata (Klotzsch) Baill.), Phyllanthus L. (P. caroliniensis Walt., $P$. niruri L., P. tenellus Roxb.), Ricinus L. (R. communis L.), Sapium P. Browne (S. glandulatum (Vell.) Pax), Savia Willd. (S. dictyocarpa Müll. Arg.), Sebastiania Spreng. (S. klotzschiana (Müll. Arg.) Müll. Arg., S. serrata (Baill.) Müll. Arg.), Securinega Com. ex A.L. Juss. (S. guaraiuva Kuhlm.).

Devido à sinonimização do gênero Chamaesyce em Euphorbia, as espécies tratadas em Chamaesyce na monografia da família Euphorbiaceae para o Parque Estadual das Fontes do Ipiranga (Cordeiro 1989), aparecem no presente trabalho em Euphorbia. Da mesma forma, Plukenetia serrata (Vell.) L.J. Gillespie foi considerada como Fragariopsis scandens A. St.-Hil., um dos seus sinônimos atuais. As espécies Sapium glandulosum (L.) Morong e Savia dictyocarpa Müll. Arg., também foram tratadas por Cordeiro (1989) pelo nome de um de seus sinônimos, respectivamente Sapium glandulatum (Vell.) Pax e Securinega guaraiuva Kuhlm. Devido a um problema de identificação as coleções de Gonatogyne brasiliensis Müll. Arg., foram erroneamente identificadas em Cordeiro (1989), como Savia dictyocarpa Müll. Arg., o que foi corrigido no presente trabalho.

Segundo dados disponíveis na literatura (Erdtman 1952, Ikuse 1956, Punt 1962, 1987, Corrêa-Gomes 1966, Salgado-Labouriau 1967, 1973, Webster \& Burch 1967, Khan 1968, Huang 1972, LozanoGarcia 1979, Meewis \& Punt 1983, El-Ghazaly 1989, Roubik \& Moreno 1991, El-Ghazaly \& Chaudhary 1993, Nowicke 1994, Takahashi et al. 1995, Carreira et al. 1996, Nowicke et al. 1998, Carneiro-Torres et al. 2002, Sagun \& van der Ham 2003, Santiago et al. 2004, Cruz-Barros et. al. 2006, Lima et al. 2007 e Silva 2008) a família Euphorbiaceae apresenta grãos de pólen em mônades, tétrades ou políades; mônades, isopolares-radiossimétricas, apolares ou heteropolares; com âmbito circular, subcircular a triangular (plano ou fossaperturado), peroblatos, oblatos, prolato-esferoidais, subprolatos, prolatos, perprolatos; inaperturados, (2-)3(-6-10)-colpados, 3-4-colporados, 5-12-colporados, 3-colpoidados, estefanocolporados; 3-6-porados, rugados, forados, foraminoidados, colpos variáveis em tamanho e forma, em geral longos, constritos ou não, operculados ou não, geral- mente finos; endoaberturas circulares, lolongadas ou lalongadas em forma de $\mathrm{X} \mathrm{e} \mathrm{H}$, sinoradas, formando um anel espiralado, às vezes com costa equatorial; exina tectada, tectado-perfurada, semitectada, psila$\mathrm{da}$, granulada, microrreticulada, reticulada, foveolada, pilada, clavada, gemada, baculada, verrugosa, escabrada, insulada, espinhosa, rugulada, microrrugulada, estriada, estriado-reticulada ou apresentando "padrão-Croton"; sexina tão espessa quanto a nexina ou mais ou menos espessa.

\section{Material e métodos}

Os botões florais utilizados para este trabalho, foram coletados de material herborizado depositado no Herbário Científico do Estado "Maria Eneyda P. Kauffmann Fidalgo" (SP). Quando os espécimes apresentavam frutos ou material polínico insuficiente, optou-se por coletas a partir de exsicatas provenientes de outras localidades. Os grãos de pólen de Ricinus communis L. não foram estudados porque a planta é invasora (Cordeiro 1989).

Os grãos de pólen foram preparados segundo o método de acetólise (Erdtman 1969). As ilustrações dos grãos de pólen acetolisados foram obtidas em microscopia óptica digitalmente, utilizandose fotomicroscópio Olympus BX 50 acoplado a uma câmara de vídeo e microcomputador (PC) e o programa Image-Pro Plus versão 3 para Windows.

Nos grãos de pólen das espécies de Croton foram medidos os diâmetros 1 (DI) e 2 (DII) e os diâmetros da unidade de ornamentação, dos lumens, mediana da subunidades, além das medidas convencionais.

Para a descrição da ornamentação da espécie Euphorbia heterophylla L. foi utilizada a nomenclatura de Hesse et al. (2009).

As lâminas com o material polínico encontram-se depositadas na palinoteca da Seção de Dicotiledôneas do Instituto de Botânica.

\section{Resultados e Discussão}

\section{Actinostemon Mart. ex Klotzsch}

\section{Actinostemon klotzschii (Didrichs) Pax}

Figuras 1-4

Forma: âmbito circular, subprolata.

Aberturas: 3-cólporos longos, estreitos; endoaberturas lalongadas.

Exina: microrreticulada, com muros arredondados; sexina mais espessa que a nexina. 
Medidas ( $\mu \mathrm{m})$ : F.C. Hoehne s.n., SP28293: $\mathrm{P}=$ $34,22 \pm 0,4 ; \mathrm{E}=26,86 \pm 0,3 ;$ diâm. equatorial em vista polar $=29,00 \pm 0,43$; colpo compr. ca. 30,57, larg. ca. 1,99; endoabertura compr. ca. 1,90, larg. ca. 2,17; exina ca. 2,98 , sexina ca. 1,59 e nexina ca. 1,25.

N. Fialho s.n., SP84312: diâm. equatorial em vista polar $=31,03$.

S.L. Jung et al. 385: diâm. equatorial em vista polar $=26,99$.

S.L. Jung et al. 395: diâm. equatorial em vista polar $=29,64$.

S.A.C. Chiea 175: diâm. equatorial em vista polar $=31,03$.

F. Barros 1029: diâm. equatorial em vista polar $=31,76$.

Observações: Os materiais da Reserva $I$. Cordeiro 347 (SP), F.C. Hoehne s.n. (SP28296), S.L. Jung 364 (SP174521), M. Kuhlmann 3685 (SP), M. Kuhlmann 3881 (SP), M. Kuhlmann s.n. (SP154964), N.A. Rosa \& J.M. Pires 3791 (SP), M.S.F. Silvestre 200 (SP169392) e M.S.F. Silvestre 206 (SP) citados por Cordeiro (1989) não foram aqui estudados por apresentarem grãos de pólen amassados ou estarem representados por frutos.

Material estudado: 5-IX-1984, F. Barros 1029 (SP); 7-VIII-1980, S.A.C. Chiea 175 (SP); 17-VII-1964, N. Fialho s.n. (SP84312); 26-IX-1931, F.C. Hoehne s.n. (SP28293); 10-VI-1981, S.L. Jung et al. 385 (SP); 15-VIII-1981, S.L. Jung et al. 395 (SP).

\section{Alchornea Sw.}

Grãos de pólen com âmbito subcircular; oblatoesferoidais a prolato-esferoidais; 3-colporados, cólporos longos, estreitos, operculados; endoaberturas lalongadas; exina microrreticulada a rugulada; sexina mais espessa que a nexina.

\section{Alchornea sidifolia Müll. Arg.}

Figuras 5-8

Forma: oblato-esferoidal.

Exina: microrreticulada.

Medidas $(\mu \mathrm{m}):$ T.M. Cerati et al. $8: \mathrm{P}=18,65 \pm$ 0,$2 ; \mathrm{E}=20,25 \pm 0,1$; diâm. equatorial em vista polar $=19,94 \pm 0,2$; colpo compr. ca. 11,05, larg. ca. 2,96, endoabertura compr. ca. 2,38, larg. ca. 6,29; exina ca. 3,16 , sexina ca. 1,91 e nexina ca. 1,39 .

F.C. Hoehne s.n., SP28432: diâm. equatorial em vista polar $=22,70$.

R.A. Pinho 33: diâm. equatorial em vista polar $=20,58$.
N.A. Rosa \& J.M. Pires 3733: diâm. equatorial em vista polar $=17,88$.

Observações: Os materiais da Reserva $A$. Custodio Filho 389 (SP), N.A. Rosa \& J.M. Pires 3754 (SP), N.A. Rosa \& J.M. Pires 3844 (SP) e M.S.F. Silvestre 227 (SP) citados por Cordeiro (1989) não foram aqui estudados por apresentarem grãos de pólen amassados ou estarem representados por frutos.

Material estudado: 10-IX-1987, T.M. Cerati et al. 8 (SP); 5-IX-1931, F.C. Hoehne s.n. (SP28432); 25-X-1963, R.A. Pinho 33 (SP); 15-XI-1980, N.A. Rosa \& J.M. Pires 3733 (SP). Os grãos de pólen de A. sidifolia foram analisados por Secco (1997) e seus resultados são semelhantes aos deste trabalho, discordando apenas quanto à ornamentação que é granulosa com numerosas perfurações no espécime estudado pelo autor. Ao observarem, sob MO e sob MEV, os grãos de pólen dessa espécie, Coelho \& Barth (2002) descreveram a ornamentação da exina como escabrada sem perfurações já nos quatro espécimes aqui examinados a ornamentação mostrouse claramente microrreticulada.

\section{Alchornea triplinervia (Spreng.) Müll. Arg.}

Figuras 9-11

Forma: prolato-esferoidal.

Exina: rugulada.

Medidas ( $\mu \mathrm{m})$ : F.C. Hoehne s.n., SP28595A: $\mathrm{P}=$ $19,63 \pm 0,1 ; \mathrm{E}=19,46 \pm 0,1$; diâm. equatorial em vista polar $=19,75 \pm 0,2$; colpo compr. ca. 11,15, larg. ca. 2,90, endoabertura compr. ca. 3,09, larg. ca. 7,29; exina ca. 3,19, sexina ca. 2,24 e nexina ca. 1,10 .

M.M.R.F. Melo 227: diâm. equatorial em vista polar $=18,84$.

Observações: $\mathrm{O}$ material da Reserva F.C. Hoehne s.n., SP28595B não foi aqui estudado por estar representado por frutos. Os grãos de pólen de Alchornea triplinervia foram descritos por Punt (1962), Coelho \& Barth (2002), Melhem et al. (2003), e Cruz-Barros et al. (2006), sendo os resultados, dos últimos autores, semelhantes aos encontrados neste trabalho, diferindo de Punt (1962) e Melhem et al. (2003), com relação à ornamentação da sexina que foi considerada por Punt (1962) como psilada, por Coelho \& Barth (2002) como escabrada com perfurações e por Melhem et al. (2003) como microrreticulada, enquanto no presente estudo observou-se que esta é rugulada. Salgado-Labouriau (1967) analisando os grãos de pólen de A. triplinervia var. genuina Müll. Arg. e var. janeirensis Müll. Arg. 
descreveu-os como oblato-esferoidais a esferoidais, com exina psilada, divergindo dos espécimes aqui estudados, cujos grãos de pólen mostraram-se prolato-esferoidais, rugulados.

Material estudado: 16-XI-1931, F.C. Hoehne s.n. (SP28595A); 25-IX-1981, M.M.R.F. Melo 227 (SP).

\section{Chave para as espécies de Alchornea}

1.Grãos de pólen oblato-esferoidais, microrreticulados A. sidifolia

1. Grãos de pólen prolato-esferoidais, rugulados A. triplinervia

\section{Croton L.}

Grãos de pólen apolares, esféricos, inaperturados, exina com padrão-Croton na qual as unidades de ornamentação têm, predominantemente, 5-8 subunidades de ornamentação; sexina bem mais espessa que a nexina.

\section{Croton floribundus Spreng.}

Figuras 12-14

Medidas $(\mu \mathrm{m}):$ R. Faria et al. s.n., SP99433: $\mathrm{DI}=$ $95,84 \pm 0,9 ;$ DII $=105,31 \pm 1,2$; diâm. da unidade ca. 13,94, diâm. do lúmen da unidade ca. 3,60, mediana da subunidade ca. 5,99; exina ca. 6,53, sexina ca. 4,69 e nexina ca. 1,81 .

L.B. Noffs et al. 39 : DI $=95,08 ; \mathrm{DII}=103,64$.

N.A. Rosa \& J.M. Pires 3728: DI = 103,74; DII $=113,56$.

Observações: Os materiais da Reserva J.C. Camargo 5 (SP), A. Custodio Filho 391 (SP), M. Goes et al. s.n. (SP204092); F.C. Hoehne s.n. (SP28526) e S.L. Jung et al. 193 (SP) citados por Cordeiro (1989) não foram aqui estudados por apresentarem grãos de pólen amassados ou estarem representados por frutos. Nowicke (1994) citou a condição inaperturada e estrutura Croton para os grãos de pólen de Croton floribundus. Estas características também foram observadas nos espécimes aqui analisados.

Material estudado: 24-XI-1966, R. Faria et al. s.n. (SP99433); 17-XI-1977, L.B. Noffs et al. 39 (SP); 15XI-1980, N.A. Rosa \& J.M. Pires 3728 (SP).

\section{Croton fuscescens Spreng.}

Figuras 15-17

Medidas ( $\mu \mathrm{m}):$ I.C.C. Macedo 10: $\mathrm{DI}=74,32 \pm$ 0,6; DII = 83,32 \pm 0,8; diâm. da unidade ca. 9,99, diâm. do lúmen da unidade ca. 2,40, mediana da subunidade ca. 3,38; exina ca. 6,92 , sexina ca. 5,19 e nexina ca. 1,93 .

J.A. Corrêa 109: DI = 82,34; DII = 89,94.

G. Davidse et al. 10483: DI $=92,62 ;$ DII $=$ 106,66 .

H. Makino 10: $\mathrm{DI}=69,82 ; \mathrm{DII}=85,51$.

H. Makino 28: $\mathrm{DI}=77,02 ; \mathrm{DII}=86,32$.

J. Mattos 12.637: DI = 82,82; DII = 91,96.

J. Mattos 13.466: DI =74,81; DII = 84,56.

Observações: Os materiais da Reserva T.M. Cerati et al. 6 (SP), C. Fonseca 11 (SP), F.C. Hoehne s.n. (SP27388), M.M.R.F.Melo 127 (SP), T. Sendulsky 478 (SP) e C.B. Toledo s.n. (SP202234) citados por Cordeiro (1989) não foram aqui estudados por apresentarem grãos de pólen amassados ou portarem apenas frutos.

Material estudado: 29-VII-1975, J.A. Corrêa 109 (SP); 21-II-1976, G. Davidse et al. 10483 (SP); 3-II1983, I.C.C. Macedo 10 (SP); 6-VI-1977, H. Makino 10 (SP); 12-V-1977, H. Makino 28 (SP); 5-I-1965, J. Mattos 12.637(SP); 7-II-1965, J. Mattos 13.466 (SP).

\section{Croton glandulosus L.}

Figuras 18-20

Medidas $(\mu \mathrm{m}): \mathrm{DI}=54,78 \pm 1,2 ; \mathrm{DII}=63,25 \pm$ 1,0; diâm. da unidade ca. 7,83, diâm. do lúmen da unidade ca. 1,95, mediana da subunidade ca. 2,77; exina ca. 7,04, sexina ca. 5,37 e nexina ca. 1,77.

Observações: Oliveira \& Santos (2000) descreveram os grãos de pólen de Croton glandulosus como apolares, grandes, esféricos, inaperturados, com padrão-Croton bem definido. Estas características também foram observadas no espécime de $C$. glandulosus do presente estudo.

Material estudado: 2-IV-1974, J.S. Silva 261 (SP).

\section{Croton lundianus ( Didr.) Müll. Arg.}

Figuras 21-23

Medidas ( $\mu \mathrm{m}):$ C.G. Fonseca $1:$ DI $=52,02 \pm$ 0,6 ; DII $=55,80 \pm 0,6$; diâm. da unidade ca. 6,32, diâm. do lúmen da unidade ca. 1,61, mediana da subunidade ca. 2,72 ; exina ca. 6,07 , sexina ca. 4,18 e nexina ca. 2,08.

M.C.B. Attié 53: $\mathrm{DI}=59,79 ; \mathrm{DII}=64,79$.

S. Chiea s.n., SP180581: DI $=54,57 ; \mathrm{DII}=61,95$.

M. Kuhlmann s.n., SP154577: DI =39,89; DII = 45,05 .

N.A. Rosa \& J.M. Pires 3743: DI =54,22; DII = 57,05 .

Observações: Os materiais da Reserva, T.P. Guerra et al. 14 (SP) e H. Makino et al. 24 (SP) ci- 

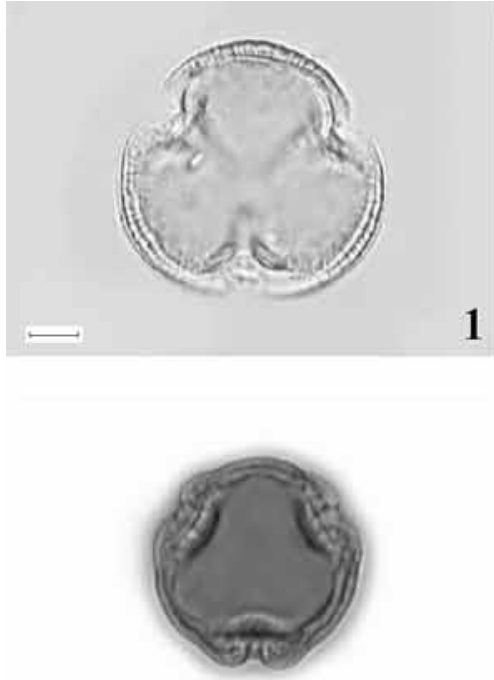

\section{5}

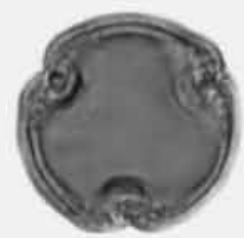

9
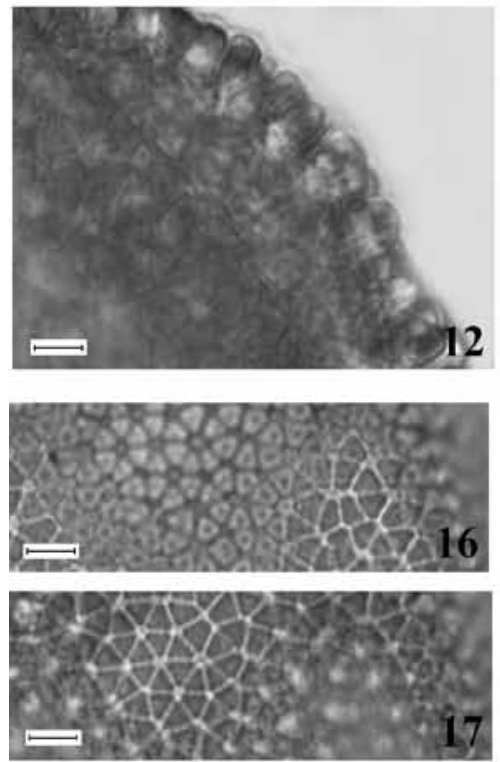
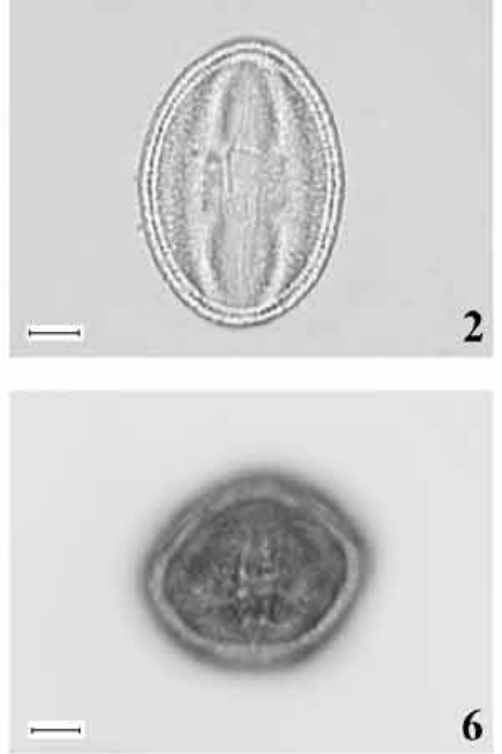

6
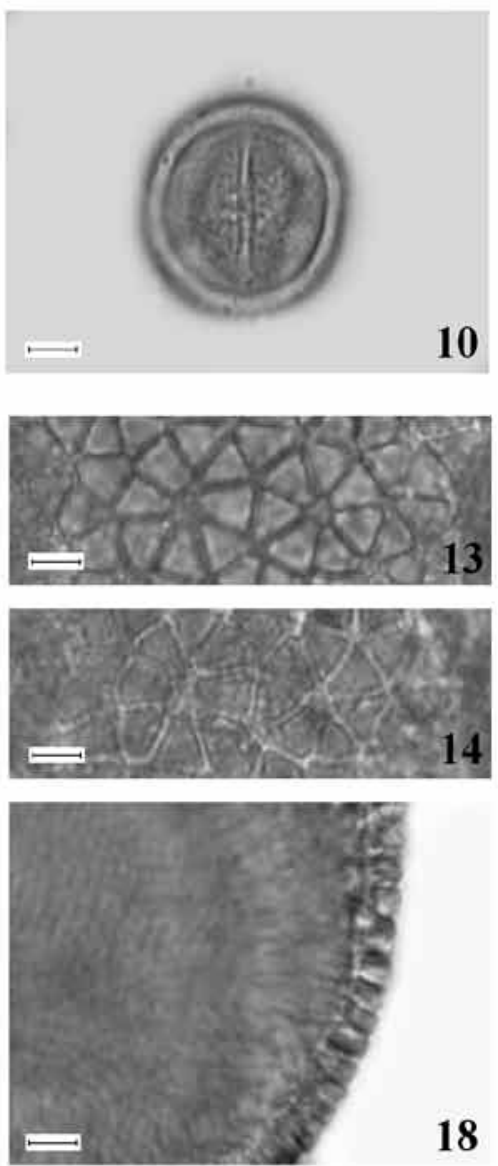

18
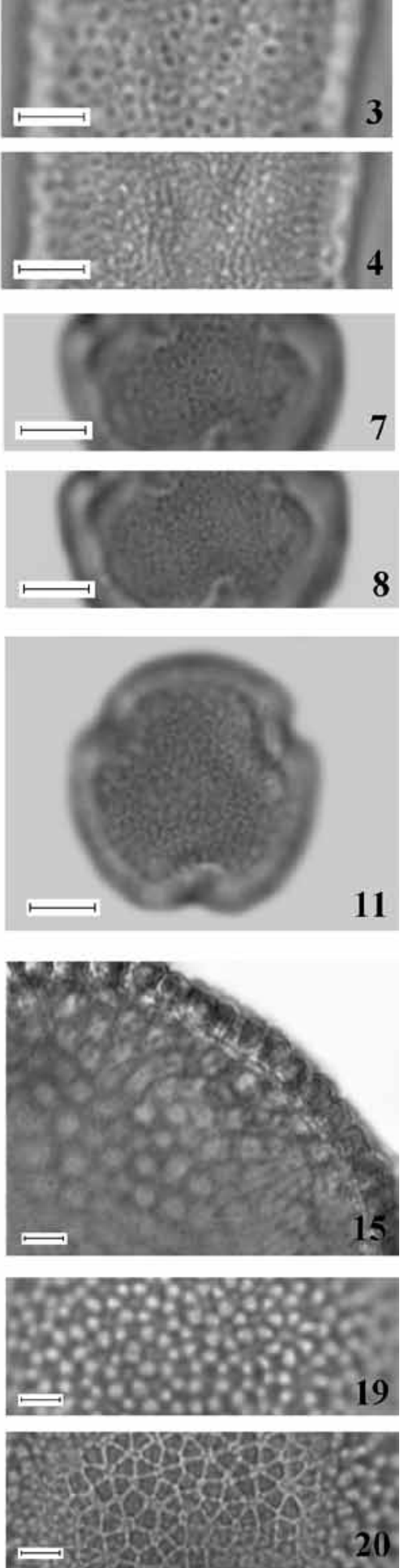

Figuras 1-20. Fotomicrografias dos grãos de pólen de Euphorbiaceae. 1-4. Actinostemon klotzchii (Didr.) Pax. 1. Vista polar. 2. Vista equatorial evidenciando o cólporo. 3-4. Análise de L.O. 5-8. Alchornea sidifolia Müll. Arg. 5. Vista polar. 6. Vista equatorial evidenciando o cólporo. 7-8. Análise de L.O. 9-11. Alchornea triplinervia (Spreng.) Müll. Arg. 9. Vista polar. 10. Vista equatorial evidenciando o cólporo. 11. Ornamentação na vista polar. 12-14. Croton floribundus Spreng. 12. Corte óptico. 13-14. Análise de L.O. Figuras 15-17. Croton fuscescens Spreng. 15. Corte óptico.16-17. Análise de L.O. 18-20. Croton glandulosus L. 18. Corte óptico. 19-20. Análise de L.O. Escalas nas figuras $=5 \mu \mathrm{m}$.

Figures 1-20. Photomicrographs of pollen grains of de Euphorbiaceae. 1-4. Actinostemon klotzchii (Didr.) Pax. 1. Polar view. 2. Equatorial view showing of aperture. 3-4. LO-analysis. 5-8. Alchornea sidifolia Müll. Arg. 5. Polar view. 6. Equatorial view showing of aperture. 7-8. LO-analysis. 9-11. Alchornea triplinervia (Spreng.) Müll. Arg. 9. Polar view. 2. Equatorial view showing of aperture. 11. Ornamentation, polar view. 12-14. Croton floribundus Spreng. 12. Optical section. 13-14. LO-analysis. 15-17. Croton fuscescens Spreng. 15. Optical section.16-17. LO-analysis. 18-20. Croton glandulosus L. 18. Optical section. 19-20. LO-analysis. Scales in the figures $=5 \mu \mathrm{m}$. 
tados por Cordeiro (1989) não foram aqui estudados por estarem representados por frutos. Os grãos de pólen de três espécimes de Croton lundianus foram analisados por Melhem et al. (2003). Os resultados apresentados pelas autoras são semelhantes aos deste trabalho.

Material estudado: 14-X-1982, M.C.B. Attié 53 (SP); 14-XI-1980, S. Chiea s.n. (SP180581); 17-I-1961, C.G. Fonseca 1 (SP); 12-III-1957, M. Kuhlmann s.n. (SP154577); 15-XI-1980, N.A. Rosa \& J.M. Pires 3743 (SP).

\section{Croton organensis Baill.}

Figuras 24-26

Medidas $(\mu \mathrm{m}): \mathrm{DI}=82,98 \pm 1,4 ; \mathrm{DII}=90,69 \pm$ 1,4; diâm. da unidade ca. 8,89, diâm. do lúmen da unidade ca. 1,68, mediana da subunidade ca. 3,57; exina ca. 6,12 , sexina ca. 4,49 e nexina ca. 1,52.

Observações: Os materiais da Reserva M. Kirizawa et al. 323 (SP), J. Mattos 13229 (SP), J. Mattos 16178 (SP), J.M. Nascimento et al. 6 (SP) e L.B. Noffs et al. 12 (SP) citados por Cordeiro (1989) não foram aqui estudados por estarem representados por frutos. Melhem et al. (2003) descreveram os grãos de pólen de Croton organensis com resultados semelhantes aos do presente estudo.

Material estudado: 14-XI-1977, M. Kirizawa 299 (SP).

\section{Croton salutaris Casar.}

Figuras 27-28

Medidas $(\mu \mathrm{m}):$ J.S. Silva 285: DI $=48,21 \pm 1,2$; DII $=52,37 \pm 1,33$; diâm. da unidade ca. 7,85, diâm. do lúmen da unidade ca. 1,43, mediana da subunidade ca. 3,43 ; exina ca. 6,35 , sexina ca. 4,99 e nexina ca. 1,42 .

F.C. Hoehne s.n., SP31388: DI $=53,03 ;$ DII $=$ 57,33 .

Material estudado: 26-XII-1933, F.C. Hoehne s.n. (SP31388); 16-IV-1974, J.S. Silva 285 (SP).

\section{Croton vulnerarius Baill.}

Figuras 29-30

Medidas ( $\mu \mathrm{m})$ : F.C. Hoehne s.n., SP28117: DI = $71,51 \pm 0,8 ;$ DII $=78,83 \pm 0,7 ;$ diâm. da unidade ca. 8,96, diâm do lúmen da unidade ca. 2,31, mediana da subunidade ca. 3,92 exina ca. 7,25, sexina ca. 5,42 e nexina ca. 1,97 .

$J . A$ Correa 43: $\mathrm{DI}=79,93 ; \mathrm{DII}=84,06$.

S.L. Jung et al. 386: DI $=60,09 ; \mathrm{DII}=67,57$.

M. Kuhlmann 3194: DI = 46,35; DII = 52,39.
Observações: Os materiais da Reserva $O$. Handro s.n. (SP32201), H. Makino 15 (SP), M.M.R.F. Melo 144 (SP), M.M.R.F. Melo 252 (SP), S.M. Saran et al. s.n. (SP196183), J.S. Silva 295 (SP), M. Sugiyama \& M. Carra 262 (SP) e M. Sugiyama et al. 520 (SP) citados por Cordeiro (1989) não foram aqui estudados estudados por apresentarem grãos de pólen amassados ou estarem representados por frutos. Não foi possível elaborar chave polínica para as sete espécies de Croton aqui estudadas, devido à semelhança morfológica entre seus grãos de pólen tanto qualitativa como quantitativamente.

Material estudado: 30-IV-1974, J.A. Correa 43 (SP); 6-VIII-1931, F.C. Hoehne s.n. (SP28117); 10-VI1981, S.L. Jung et al. 386 (SP174524); 20-III-1946, M. Kuhlmann 3194 (SP).

\section{Dalechampia L}

\section{Dalechampia triphylla Lam.}

Figuras 31-34

Forma: prolato-esferoidal; âmbito circular.

Aberturas: 3-cólporos curtos, estreitos; endoaberturas endocinguladas, com costa.

Exina: reticulada, muros sinuosos; sexina mais espessa que a nexina.

Medidas $(\mu \mathrm{m})$ : H. Makino \& D.A. Grande 139: $\mathrm{P}=63,26 \pm 0,63 ; \mathrm{E}=58,02 \pm 0,57$; diâm. equatorial em vista polar $=55,24 \pm 0,63$; colpo compr. ca. 33,26 , larg. ca. 3,86, endoabertura compr. ca. 5,12; exina ca. 6,46, sexina ca. 4,22 e nexina ca. 2,26.

F. Barros 849: diâm. equatorial em vista polar $=62,39$.

S.L. Jung et al. 183: diâm. equatorial em vista polar $=66,86$.

M. Kirizawa \& M.G.L. Wanderley s.n., SP150934: diâm. equatorial em vista polar $=53,73$.

M.S.F. Silvestre 9: diâm. equatorial em vista po$\operatorname{lar}=61,73$.

Observações: Os materiais da Reserva M.M.R.F. Melo 41 (SP), M.M.R.F. Melo 65 (SP), M.M.R.F. Melo 124 (SP), T. Sendulsky 427 (SP), M.S.F. Silvestre 11 (SP), e M.S.F. Silvestre 235 (SP), citados por Cordeiro (1989) não foram aqui estudados por apresentarem grãos de pólen amassados ou estarem representados por frutos.

Material estudado: 30-VI-1983, F. Barros 849 (SP); 11-X-1977, S.L. Jung et al. 183 (SP); 20-IX-1976, M. Kirizawa \& M.G.L. Wanderley s.n. (SP150934); 12IX-1978, H. Makino \& D.A. Grande 139 (SP); 31III-1977, M.S.F. Silvestre 9 (SP). 


\section{Euphorbia L.}

Grãos de pólen com âmbito subcircular, prolatos a prolato-esferoidais; 3-colporados, colpos longos, com margem, endoaberturas lalongadas a lolongadas, com margem; exina reticulado-cristada a microrreticulada; sexina mais espessa que a nexina.

\section{Euphorbia heterophylla L.}

Figuras 35-38

Forma: prolato-esferoidal.

Abertura: endoaberturas lalongadas.

Exina: reticulado-cristada ou seja retículos apresentando muros com elementos de escultura proeminentes, heterorreticulada.

Medidas $(\mu \mathrm{m}): \mathrm{P}=53,83 \pm 0,8 ; \mathrm{E}=47,95 \pm 0,7 ;$ diâm. equatorial em vista polar $=54,01 \pm 0,8$; colpo compr. ca. 32,86, larg. ca. 3,48, endoabertura compr. ca. 4,96 , larg. ca. 9,72; exina ca. 6,19 , sexina ca. 5,50, teto ca. 3,76 e nexina ca. 1,16 .

Observações: Os materiais da Reserva S. Romaniuc Neto 149 (SP) e N.A. Rosa \& J.M. Pires 3825 (SP) citados por Cordeiro (1989) não foram aqui estudados por apresentarem grãos de pólen amassados ou estarem representados por frutos. Os grãos de pólen de Euphorbia heterophylla foram estudados por Roubik \& Moreno (1991) e por Carneiro-Torres et al. (2002) sob o nome de Poinsettia heterophylla (L.) Klotzch \& Garcke apresentando resultados muito semelhantes aos aqui analisados, divergindo apenas quanto ao tamanho dos grãos de pólen que são significativamente menores nos espécimes estudados por Carneiro-Torres et al. (2002). Com relação à ornamentação Roubik \& Moreno (1991) e Carneiro-Torres et al. (2002) descreveram-na respectivamente como reticulado-heterobrocada e reticulada com columelas heterogêneas, enquanto que no presente trabalho observou-se que ela é reticulado-cristada. El-Ghazaly \& Chaudary (1993) e Perveen \& Qaiser (2005) descreveram os grãos de pólen de E. heterophylla e seus resultados de um modo geral são semelhantes aos aqui encontrados, havendo diferenças somente no tamanho dos grãos de pólen analisados por El-Ghazaly \& Chaudary (1993) que são significativamente menores.

Material estudado: BRASIL. AmazonAs: Humaitá, 18-XI-1977, N.B.M. Brantjes 700304 (SP154714).

\section{Euphorbia hirta L.}

Figuras 39-42

Forma: prolata.
Aberturas: endoaberturas lalongadas.

Exina: microrreticulada.

Medidas $(\mu \mathrm{m}): \mathrm{P}=24,50 ; \mathrm{E}=18,30$; diâm. equatorial em vista polar $=20,48$; exina ca. 3,25 , colpo compr. ca. 18,51, larg. ca. 3,33, endoabertura compr. ca. 3,65, larg. ca. 7,54; exina ca. 3,25, sexina ca. 1,55, teto ca. 1,07 e nexina ca. 1,31.

Observações: O material da Reserva M.A. Pereira s.n. (SP53374), citado por Cordeiro (1989) não foi aqui estudado por apresentar grãos de pólen amassados. Os grãos de pólen de Euphorbia hirta foram estudados por Roubik \& Moreno (1991) e por Carneiro-Torres et al. (2002) sob o nome de Chamaesyce hirta (L.) Millsp. As descrições gerais apresentadas por esses autores concordam com os dados aqui obtidos. Punt (1962), El-Ghazaly \& Chaudary (1993) e Perveen \& Qaiser (2005) descreveram os grãos de pólen de E. hirta. Constatou-se uma divergência em relação à exina, que foi descrita como psilada (Punt 1962), perfurada a mais ou menos microrreticulada (El-Ghazaly \& Chaudary 1993) a finamente reticulada (Perveen \& Qaiser 2005). No presente estudo a ornamentação da exina foi definida como microrreticulada. Quanto ao tamanho os grãos de pólen examinados por Punt (1962) e Perveen \& Qaiser (2005) são respectivamente maiores e menores que os aqui estudados.

Material estudado: Brasil: MinAs GeraIs: Leopoldina, 7-IV-1977, B. Larcher 14744 (SP).

\section{Euphorbia hyssopifolia L.}

Figuras 43-46

Forma: prolata.

Abertura: endoabertura lalongada

Exina: microrreticulada.

Medidas $(\mu \mathrm{m}): \mathrm{P}=31,01 ; \mathrm{E}=20,44$; diâm. equatorial em vista polar $=20,30$; colpo compr. ca. 26,88 , larg. ca. 3,64 , endoabertura compr. ca. 4,85, larg. ca. 10,39; exina ca. 3,54, sexina ca. 2,37 , teto ca. 0,93 e nexina ca. 1,24 .

Observações: Os grãos de pólen de Euphorbia hyssopifolia foram estudados por Roubik \& Moreno (1991) e por Carneiro-Torres et al. (2002) sob o nome de Chamaesyce hyssopifolia (L.) Small. Quanto à abertura somente Roubik \& Moreno (1991) observaram a presença de costa no colpo formando uma fina margem. No presente estudo foi observada, apenas a presença de margem. Quanto à forma Roubik \& Moreno (1991) descreveram-na como subprolata, Carneiro-Torres et al. (2002) como prolata a subpro- 

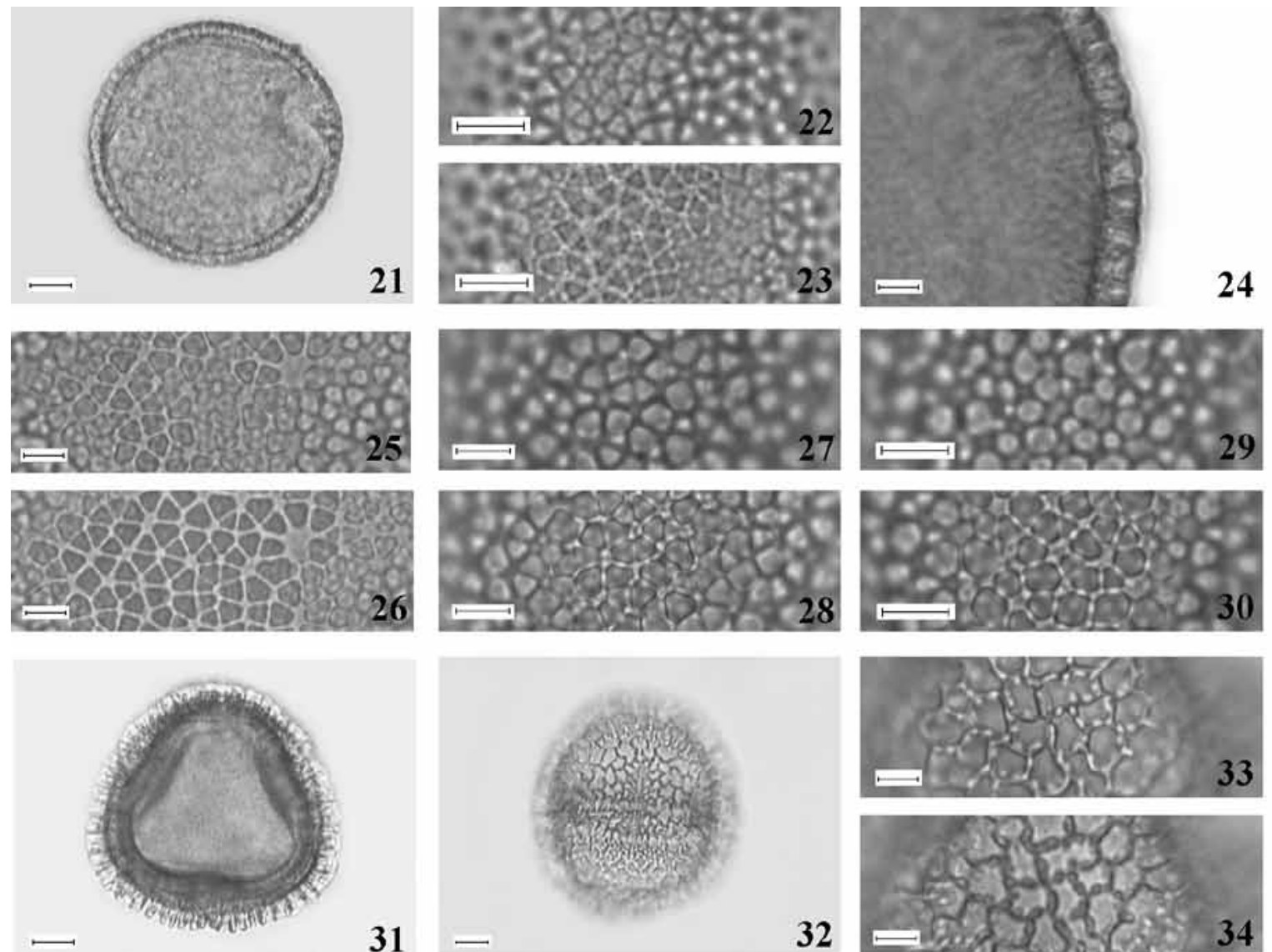

31
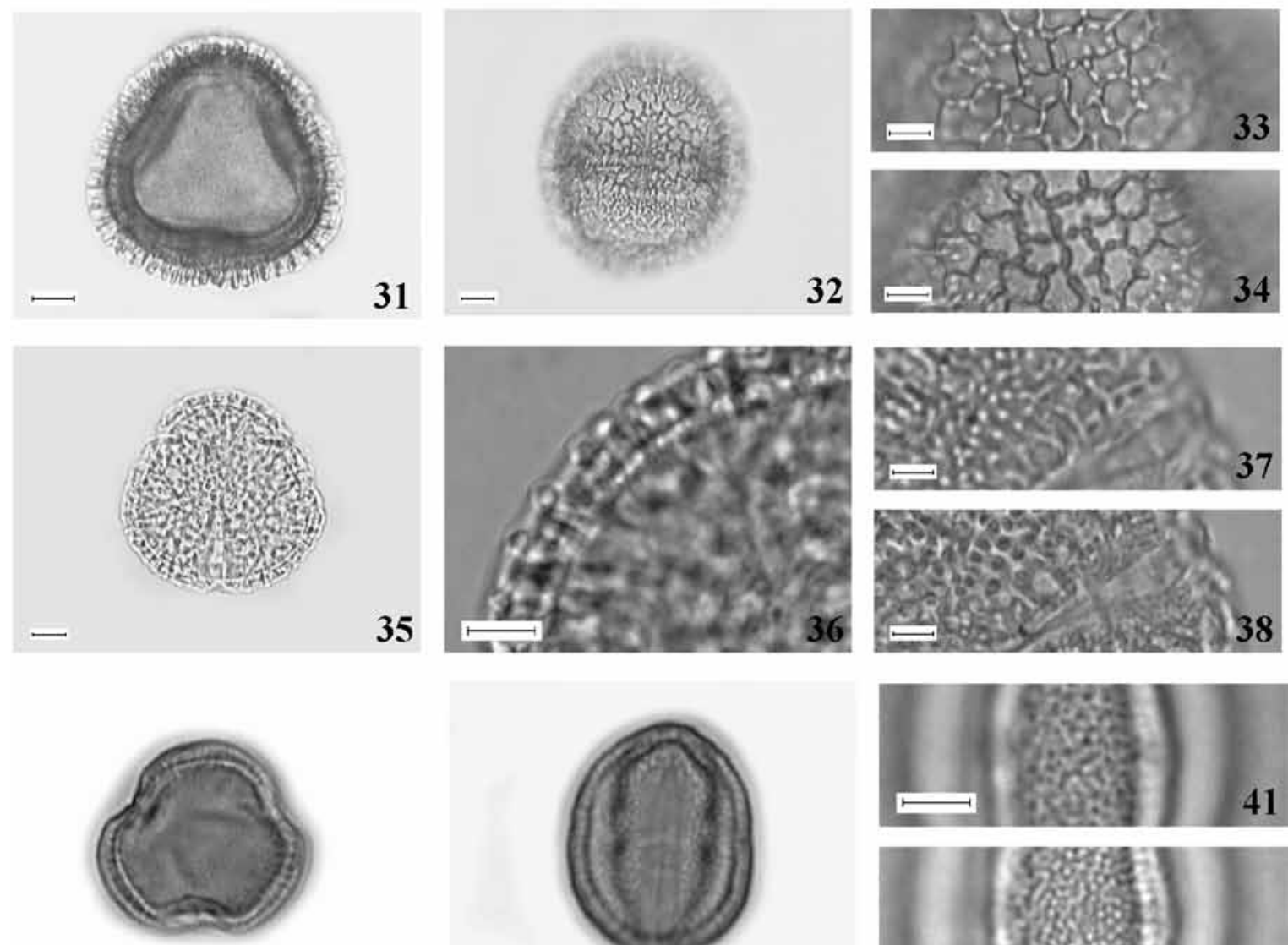

39
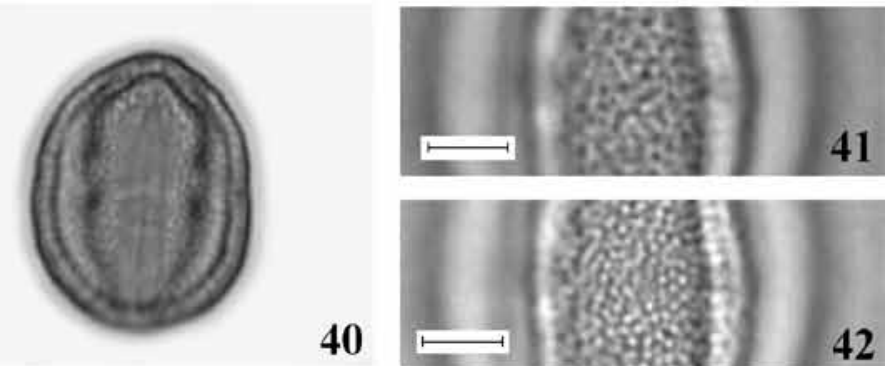

Figuras 21-42. Fotomicrografias dos grãos de pólen de Euphorbiaceae. 21-23. Croton lundianus (Didr.) Müll. Arg. 21. Vista geral do grão de pólen. 22-23. Análise de L.O. 24-26. Croton organensis Baill. 24. Corte óptico. 25-26. Análise de L.O. 27-28. Croton salutaris Casar. Análise de L.O. 29-30. Croton vulnerarius Baill. Análise de L.O. 31-34. Dalechampia triphylla Lam. 31. Vista polar. 32. Vista equatorial evidenciando o cólporo. 33-34. Análise de L.O. 35-38. Euphorbia heterophylla L. 35. Vista polar. 36. Corte óptico. 37-38. Análise de L.O. 39-42. Euphorbia hirta (L.) Millsp. 39. Vista polar. 40. Vista equatorial evidenciando o cólporo. 41-42. Análise de L.O. Escalas nas figuras $21,31-32,35=10 \mu \mathrm{m}$; demais figuras $=5 \mu \mathrm{m}$.

Figures 21-42. Photomicrographs of pollen grains of de Euphorbiaceae. 22-23. Croton lundianus (Diedr.) Müll. Arg. 21. General view of pollen grains. 22-23 LO-analysis. 24-26. Croton organensis Baill. 24. Optical section. 25-26. LO-analysis. 27-28. Croton salutaris Casar. LO-analysis. 29-30. Croton vulnerarius Baill. LO-analysis. 31-34. Dalechampia triphylla Lam. 31. Polar view. 32. Equatorial view showing aperture. 33-34. LO-analysis. 35-38. Euphorbia heterophylla L. 35. polar view. 36. Equatorial view, showing the aperture. 37-38. LO-analysis. 39-42. Euphorbia hirta (L.) Millsp. 39. Polar view. 40. Equatorial view showing of aperture. 41-42. LO-analysis. Scales in the figures $21,31-32,35=10 \mu \mathrm{m}$; remaining figures $=5 \mu \mathrm{m}$. 
lata, enquanto no presente estudo observou-se que ela é prolata.

Material estudado: XII-1987, I. Cordeiro 474 (SP).

\section{Euphorbia peplus L.}

Figuras 47-50

Forma: prolato-esferoidal.

Abertura: endoabertura lolongada de difícil visualização.

Exina: microrreticulada.

Medidas $(\mu \mathrm{m}): \mathrm{P}=25,12 \pm 0,5 ; \mathrm{E}=23,03 \pm 0,6$; diâm. equatorial em vista polar $=27,69 \pm 0,5$; colpo compr. ca. 15,05, larg. ca. 1,40, endoabertura compr. ca. 8,68 , larg. ca. 2,14 ; exina ca. 3,24 , sexina ca. 2,43 , teto ca. 1,56 e nexina ca. 0,87 .

Observações: O material da Reserva T. Sendulsky 808 (SP) citado por Cordeiro (1989) não foi aqui estudado por apresentar grãos de pólen amassados. El-Ghazaly \& Chaudhary (1993) ao estudarem três espécimes de E. peplus, mencionaram endoaberturas variando de esferoidais, lalongadas, lolongadas até em forma de " $H$ ", enquanto que no espécime aqui estudado estas foram definidas como lolongadas. Os grãos de pólen de E. peplus foram inseridos por Punt (1962) no tipo E. hirta indicando que estes são muito semelhantes, apresentando endoaberturas lalongadas e exina psilada, entretanto no presente estudo essas duas espécies diferem entre si, pois constatou-se que a endoabertura de E. peplus é lolongada e sua exina microrreticulada.

Material estudado: BRASIL. São PAUlo: São Paulo, Butantã, 25-X-1921, A. Gehrt s.n. (SP7151).

\section{Chave para as espécies de Euphorbia}

1. Grãos de pólen com exina reticulado-cristada E. heterophylla

1. Grãos de pólen com exina microrreticulada

2. Grãos de pólen prolato-esferoidais, endoaberturas lolongadas E. peplus

2. Grãos de pólen prolatos, endoaberturas lalongadas E. hirta E. hyssopifolia

Gonatogyne Müll. Arg.

1. Gonatogyne brasiliensis Müll. Arg.

Figuras 51-54

Forma: oblato-esferoidal; âmbito subtriangular.

Aberturas: 3-cólporos longos, largos; endoabertura lalongada.
Exina: reticulada; sexina mais espessa que a nexina.

Medidas $(\mu \mathrm{m})$ : I. Cordeiro \& G.L. Esteves 1384: $\mathrm{P}=31,38 \pm 0,3 ; \mathrm{E}=33,74 \pm 0,2$; diâm. equatorial em vista polar $=34,04 \pm 0,2$; colpo compr. ca. 17,39, larg. ca. 2,32, endoabertura compr. ca. 4,74, larg. ca. 13,39; exina ca. 2,71 , sexina ca. 1,49 e nexina ca. 1,23 .

F.C. Hoehne s.n., SP29617: $\mathrm{P}=31,61 ; \mathrm{E}=34,93$.

Observações: Os materiais da Reserva F.C. Hoehne s.n. (SP27387A), F.C. Hoehne s.n. (SP27387B), F.C. Hoehne s.n. (SP29503), F.C. Hoehne s.n. (SP29651) e N.A. Rosa \& J.M. Pires 3982 citados por Cordeiro (1989) não foram aqui estudados por estarem em fruto ou com grão de pólen amassados. O material da Reserva I. Cordeiro \& G.L. Esteves 1384 (SP) não constava da citação de Cordeiro (1989) tendo sido posteriormente identificado como Gonatogyne brasiliensis e incluído no presente trabalho, visando uma melhor caracterização da espécie.

Material estudado: IV-1994, I. Cordeiro \& G.L. Esteves 1384 (SP269121); 16-VI-1932, F.C. Hoehne s.n. (SP29617).

\section{Hieronyma Allemão}

\section{Hieronyma alchorneoides Allemão}

Figuras 55-57

Forma: prolata; âmbito subtriangular.

Aberturas: 3-cólporos longos, estreitos; endoaberturas lalongadas com costa.

Exina: microrreticulada; sexina mais espessa que a nexina.

Medidas $(\mu \mathrm{m}): \mathrm{P}=47,09 \pm 0,5 ; \mathrm{E}=35,15 \pm 0,3$; colpo compr. ca. 33,23 , larg. ca. 2,74 , endoabertura compr. ca. 5,42, larg. ca. 13,30; exina ca. 2,05, sexina ca. 1,15 e nexina ca. 0,90 .

Observações: O material da Reserva $M$. Kuhlmann 3200 (SP) citado por Cordeiro (1989) não foi aqui estudado por estar em fruto. $H$. alchorneoides foi examinada palinologicamente por Punt (1962) e Roubik \& Moreno (1991), neste último trabalho citada como H. laxiflora (Tul) Müll. Arg., um de seus sinônimos. Houve divergência quanto ao tipo de ornamentação, pois Punt (1962) descreveu-a como psilada e Roubik \& Moreno (1991) como reticulada, enquanto no presente estudo observou-se que ela é microrreticulada. Com relação ao tamanho, os grãos de pólen do espécime aqui estudado são significativamente maiores que os examinados por Punt (1962) e Roubik \& Moreno (1991). 
Material estudado: BRASIL. SÃo PAULO: São Paulo, Horto Florestal, 24-I-1946, J.P. Coelho s.n. (SP296594).

\section{Maprounea Aubl.}

\section{Maprounea guianensis Aubl.}

Figuras 58-61

Forma: subprolata; âmbito subtriangular.

Aberturas: 3-cólporos longos, estreitos; endoaberturas lalongadas.

Exina: microrreticulada; sexina mais espessa que a nexina.

Medidas $(\mu \mathrm{m}): \mathrm{P}=25,61 \pm 0,3 ; \mathrm{E}=20,05 \pm 0,3$; diâm. equatorial em vista polar $=21,40 \pm 0,3$; colpo compr. ca. 16,98, larg. ca. 1,96, endoabertura compr. ca. 2,38 , larg. ca. 4,32; exina ca. 2,78 , sexina ca. 1,13 , teto ca. 0,55 e nexina ca. 1,07.

Observações: Os grãos de pólen dessa espécie foram estudados por Punt (1962) apresentando resultados muito semelhantes aos aqui obtidos, divergindo apenas quanto à ornamentação da exina que, para o autor, é psilada.

Material estudado: 29-XI-1934, F.C. Hoehne s.n. (SP32166).

Pera Mutis

1. Pera obovata (Klotzsch) Baill.

Figuras 62-65

Forma: prolato-esferoidal; âmbito circular

Aberturas: 3-4-cólporos longos, com margem; endoaberturas lalongadas com margem.

Exina: microrreticulada; nexina mais espessa que a sexina.

Medidas $(\mu \mathrm{m})$ : F.C. Hoehne s.n. (SP27423): $\mathrm{P}=20,92 \pm 0,2 ; \mathrm{E}=18,90 \pm 0,1 ;$ diâm. equatorial em vista polar 3 -colporado $=18,94 \pm 0,2$; diâm. equatorial em vista polar 4-colporado $=18,74 \pm 0,2$; colpo compr. ca. 11,04 , larg. ca. 1,23 , endoabertura compr. ca. 2,29, larg. ca. 4,01; exina ca. 2,15 , sexina ca. 0,85 e nexina ca. 1,29 .

J.S. Silva 332: $\mathrm{P}=19,86 ; \mathrm{E}=18,60$.

Observações: Os materiais da Reserva $M$. Kuhlmann 3197 (SP) e N.A. Rosa \& Pires 3855 (SP) citados por Cordeiro (1989) não foram aqui estudados por estarem em fruto. Os grãos de pólen de P. obovata foram inseridos por Nowicke et al. (1998) no tipo polínico Pera parvifolia por apresentarem aberturas sem margem e opérculos e exina perfurada, já para Coelho \& Barth (2002), estes foram inseridos no tipo Pera por apresentarem aberturas sem margem e opérculos e com exina microrreticulada. Os espécimes aqui analisados mostraram aberturas com margem e exina microrreticulada.

Material estudado: 9-XII-1931, F.C. Hoehne s.n. (SP27423); 25-VI-1974, J.S. Silva 332 (SP).

\section{Phyllanthus L.}

Grãos de pólen com âmbito circular, prolatos a subprolatos; 4-colporados, colpos longos estreitos, com margem, endoaberturas lalongadas, com costa; exina microrreticulada; sexina mais espessa que a nexina.

\section{Phyllanthus caroliniensis Walt.}

Figuras 66-68

Forma: prolata.

Medidas $(\mu \mathrm{m}): G$. Eiten \& L.T. Eiten 2749: $\mathrm{P}=$ $19,81 \pm 0,2 ; \mathrm{E}=13,19 \pm 0,2$; colpo compr. ca. 15,66, larg. ca. 5,98, endoabertura compr. ca. 1,64, larg. ca. 2,04; exina ca. 2,12, sexina ca. 1,11 e nexina ca. 1,00 .

M. Kuhlmann 3196: $\mathrm{P}=39,13 ; \mathrm{E}=27,83$.

Observações: O material da Reserva G. Eiten \& L.T. Eiten 2750 (SP) citado por Cordeiro (1989) não foi aqui estudado por apresentarem grãos de pólen amassados. Os grãos de pólen de Phyllanthus caroliniensis foram descritos por Punt (1987) e Silva (2008) como 4-colporados, prolatos. Entretanto observou-se uma divergência quanto à ornamentação que foi considerada como reticulada (Punt 1987) e microrreticulada (Silva 2008). Os dois espécimes aqui analisados apresentaram exina microrreticulada, concordando com os dados de Silva (2008).

Material estudado: 24-IV-1961, G. Eiten \& L.T. Eiten 2749 (SP); 13-III-1945, M. Kuhlmann 3196 (SP).

\section{Phyllanthus niruri L.}

Figuras 69-71

Forma: prolata.

Medidas $(\mu \mathrm{m}): \mathrm{P}=32,96 \pm 0,3 ; \mathrm{E}=16,87 \pm 0,3$; colpo compr. ca. 10,36, larg. ca. 2,78, endoabertura compr. ca. 35,24, larg. ca. 4,16; exina ca. 2,81, sexina ca. 1,33 , e nexina ca. 1,36 .

Observações: O material da Reserva G. Davidse \& W.G. D'Arcy 10442 citado por Cordeiro (1989) não foi aqui estudado por apresentar grãos de pólen amassados. $P$. niruri foi palinologicamente estudada por Punt (1962), Webster \& Burch (1967), e Silva (2008). Os referidos autores mencionaram para a espécie grãos de pólen 4-colporados, com exina 

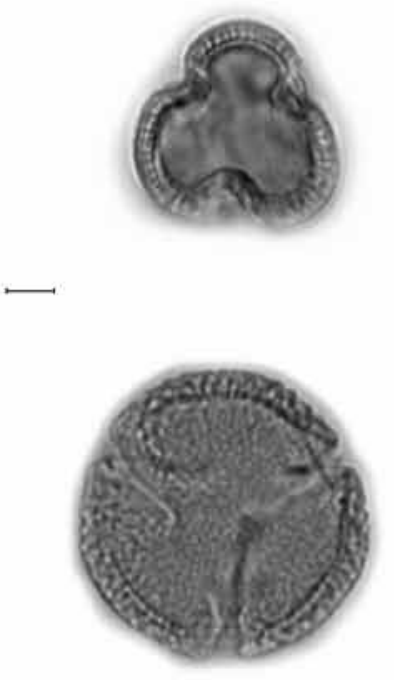

47

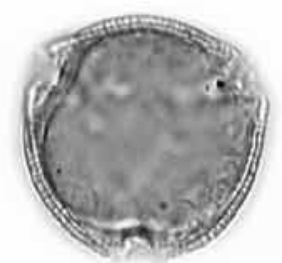

51

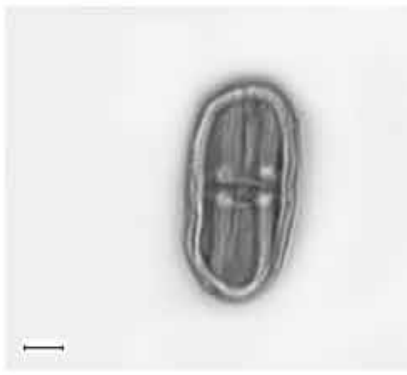

55
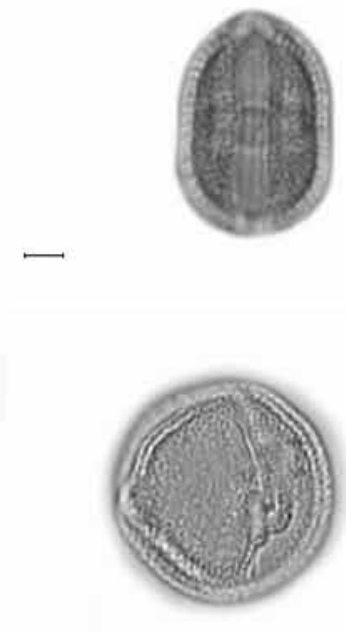

43

7
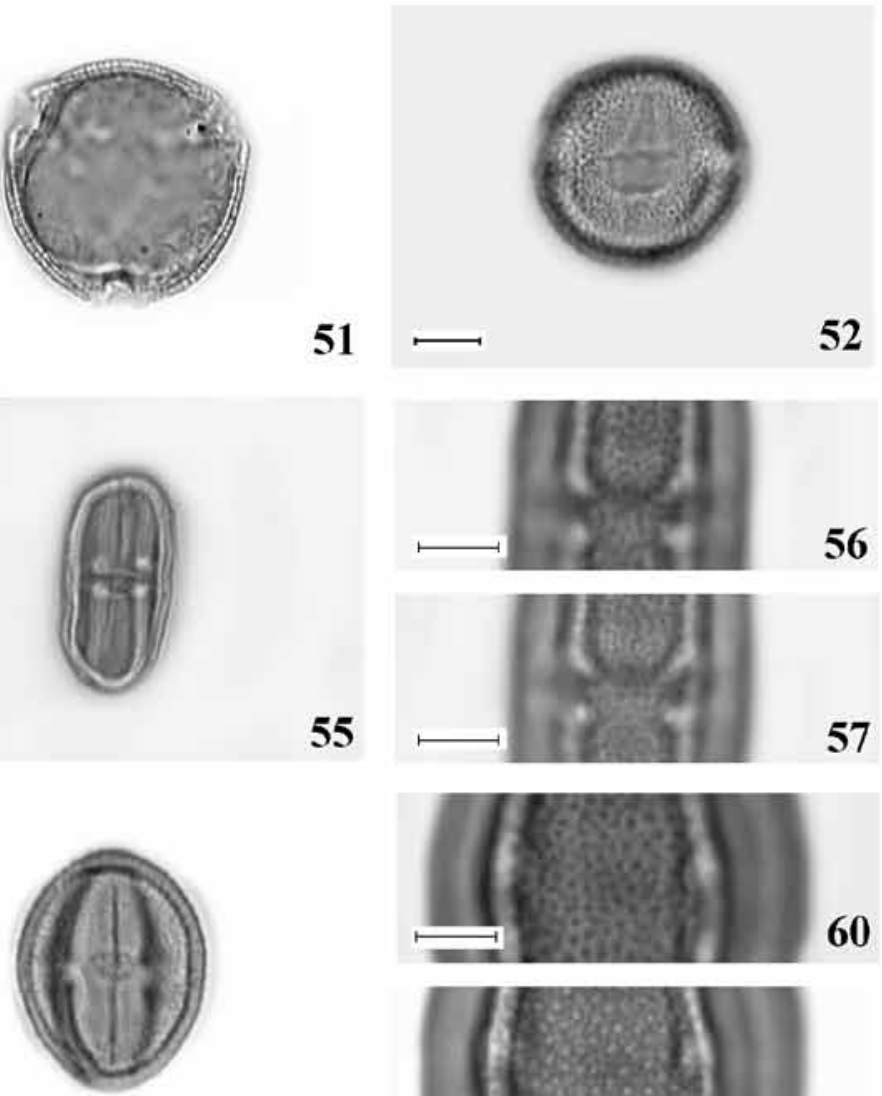

59

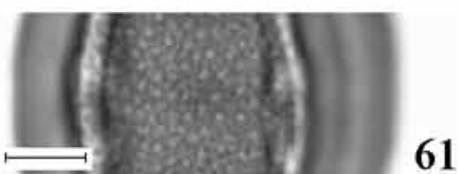

52

56

57

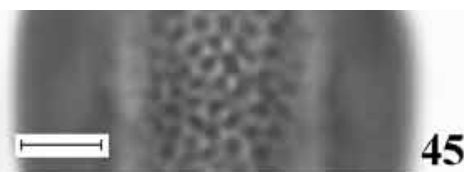

44
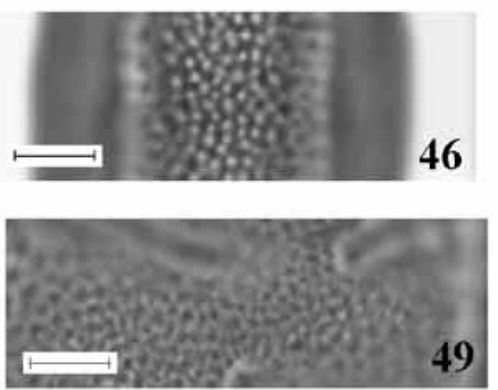

48
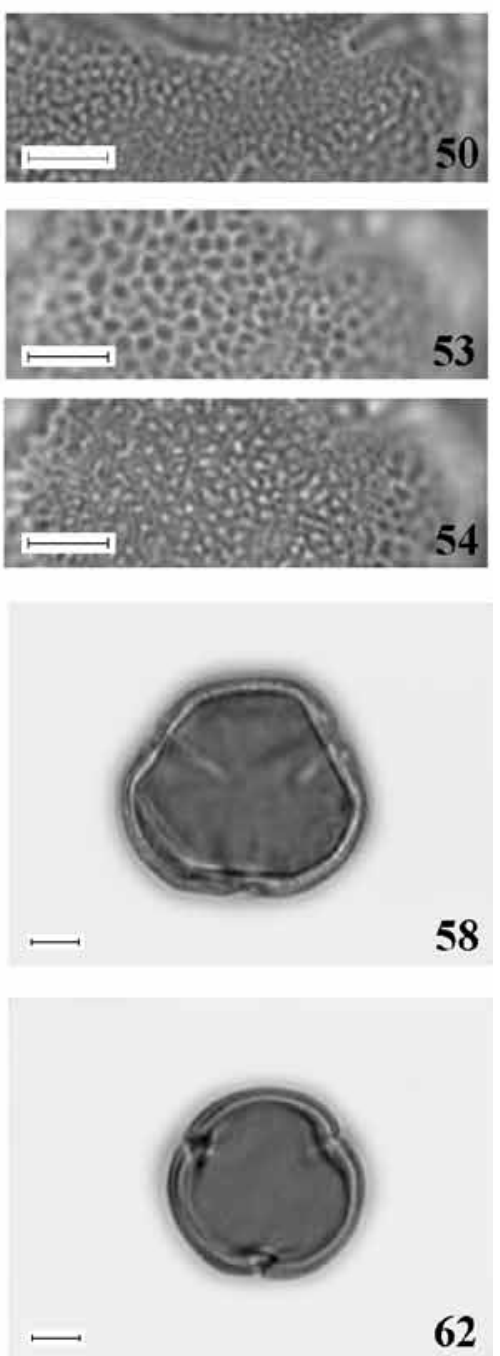

Figuras 43-62. Fotomicrografias dos grãos de pólen de Euphorbiaceae. 43-46. Euphorbia hyssopifolia (L.) Small. 43. Vista polar. 44. Vista equatorial evidenciando o cólporo. 45-46. Análise de L.O. 47-50. Euphorbia peplus L. 47. Vista polar. 48. Vista equatorial evidenciando o cólporo. 49-50. Análise de L.O. Figuras 51-54. Gonatogyne brasiliensis Müll. 51. Vista polar. 52. Vista equatorial, evidenciando o cólporo 53-54. Análise de L.O. 55-57. Hieronyma alchorneoides Allemão. 55. Vista equatorial evidenciando o cólporo. 56-57. Análise de L.O. 58-61. Maprounea guianensis Aubl. 58. Vista polar. 59. Vista equatorial evidenciando o cólporo. 60-61. Análise de L.O. 62. Pera obovata (Klotzsch) Baill. Vista polar. Escalas nas figuras 48, 51-52 $=10 \mu \mathrm{m}$, demais figuras $=5 \mu \mathrm{m}$.

Figures 43-62. Photomicrographs of pollen grains of de Euphorbiaceae. 43-46. Euphorbia hyssopifolia (L.) Small. 43. Polar view. 44. Equatorial view, showing the aperture. 45-46. LO-analysis. 47-50. Euphorbia peplus L. 47. Polar view. 48. Equatorial view showing the aperture. 49-50. LO-alalysis. 51-54. Gonatogyne brasiliensis Müll. 51. Polar view. 52. Equatorial view showing the 53-54. Análise de L.O. 55-57. Hieronyma alchorneoides Allemão. 55. Equatorial view showing the aperture. 56-57. LO-analysis. 58-61. Maprounea guianensis Aubl. 58. Polar view. 59. Equatorial view showing the aperture. 60-61. LO-analysis. 62. Pera obovata (Klotzsch) Baill. Polar view. Scales in the figures $48,51-52=10 \mu \mathrm{m}$, remaining figures $=5 \mu \mathrm{m}$. 
reticulada. Os resultados aqui obtidos diferem dos autores supracitados quando se considerou a ornamentação da exina.

Material estudado: Brasil: SÃo PAuLo: Cananéia, Ilha do Cardoso, 15-X-1986, G.L. Webster 25560 (SP).

\section{Phyllanthus tenellus Roxb.}

Figuras 72-75

Forma: subprolata.

Medidas $(\mu \mathrm{m}): \mathrm{P}=20,24 \pm 0,1 ; \mathrm{E}=17,10 \pm 0,2$; colpo compr. ca. 15,34 , larg. ca. 4,24, endoabertura compr. ca. 3,80, larg. ca. 4,97; exina ca. 2,51 , sexina ca. 1,35 e nexina ca. 1,16 .

Observações: Os materiais da Reserva G. Eiten \& L.T. Eiten 2751 (SP) e F.C. Hoehne s.n. (SP32199) citados por Cordeiro (1989) não foram aqui estudados por apresentarem grãos de pólen amassados. Silva (2008), ao estudar dois espécimes de P. tenellus, enquadrou-os dentro do tipo polínico 4-colporados, apresentando exina microrreticulada. Os resultados obtidos no presente estudo corroboram os de Silva (2008).

Material estudado: BRASIL. SÃo PAULo: São Paulo, Alto de Pinheiros, 20-V-1998, M.S.F. SilvestreCapelato 258 (SP).

Chave para as espécies de Phyllanthus

1. Grãos de pólen subprolatos P. tenellus

1. Grãos de pólen prolatos P.niruri P. caroliniensis

\section{Plukenetia L.}

\section{Plukenetia serrata (Vell.) L.J. Gillespie}

Figuras 76-79

Forma: oblato-esferoidal; âmbito subtriangular.

Aberturas: 3-colpados; colpos de difícil visualização em vista equatorial, com margem.

Exina: reticulada, heterorreticulados, muros sinuosos; sexina mais espessa que a nexina.

Medidas $(\mu \mathrm{m}): \mathrm{P}=33,05 ; \mathrm{E}=36,15$; diâm. equatorial em vista polar $=40,06$; exina ca. 3,07 , sexina ca. 1,79 e nexina ca. 1,28.

Observações: Os materiais da Reserva F.C. Hoehne s.n. (SP29250) M. Kuhlmann s.n. (SP52362) e M. Kuhlmann 3199 (SP) citados por Cordeiro (1989) não foram aqui estudados por apresentarem grãos de pólen amassados. Os grãos de pólen dessa espécie foram estudados por Punt (1962) sob o nome de Fragariopsis scandens, um de seus sinônimos, apresen- tando resultados muito semelhantes aos aqui obtidos. Material estudado: BRASIL. São PAULo: Ubatuba, 10-III-1989, A. Furlan et al. 655 (SP).

Sapium P. Browne

\section{Sapium glandulosum (L.) Morong}

Figuras 80-83

Forma: subprolata, âmbito subcircular.

Aberturas: 3-cólporos; endoaberturas lalongadas.

Exina: rugulada; sexina mais espessa que a nexina.

Medidas $(\mu \mathrm{m}): \mathrm{P}=46,03 \pm 0,4 ; \mathrm{E}=35,73 \pm 0,4 ;$ colpo compr. ca. 35,74 , larg. ca. 2,45, endoabertura compr. ca. 4,56, larg. ca. 25,72 ; exina ca. 3,40 , sexina ca. 2,36 e nexina ca. 1,31 .

Observações: Os materiais da Reserva $O$. Handro s.n. (SP40815), F.C. Hoehne s.n. (SP28428) e N.A. Rosa \& J.M. Pires 3778 (SP) citados por Cordeiro (1989) não foram aqui estudados por apresentarem grãos de pólen amassados.

Material estudado: 23-X-1980, A. Custodio Filho 386 (SP).

\section{Savia Willd.}

1. Savia dictyocarpa Müll. Arg.

Figuras 84-87

Forma: subprolata; âmbito subcircular.

Aberturas: 3-cólporos longos, com margem; endoaberturas lalongadas, constritas na região mediana, com terminações de difícil visualização.

Exina: microrreticulada.

Medidas $(\mu \mathrm{m}):$ M. Kuhlmann s.n., SP52789: $\mathrm{P}=$ $20,27 \pm 0,3 ; E=16,98 \pm 0,3$; diâm. equatorial em vista polar $=17,91 \pm 0,3$; colpo compr. ca. 11,70 , larg. ca. 1,89 ; exina ca. 1,71 , sexina ca. 0,81 e nexina ca. 0,75 .

M. Kuhlmann s.n., SP55632: diâm. equatorial em vista polar $=22,29$.

Observações: Os materiais da Reserva J.C. Camargo 14 (SP), M. Kuhlmann 3201 (SP), M. Kuhlmann 3202 (SP), M. Kuhlmann 3687 (SP), citados por Cordeiro (1989) não foram aqui estudados por apresentarem grãos de pólen amassados. As endoaberturas não foram medidas por serem de difícil visualização.

Material estudado: 18-X-1955, M. Kuhlmann s.n. (SP52789); 5-XI-1955, M. Kuhlmann s.n. (SP55632). 


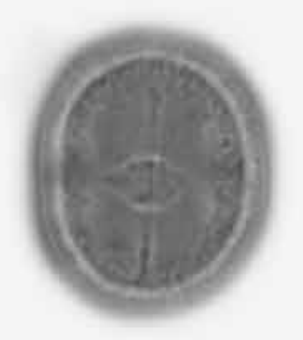

63

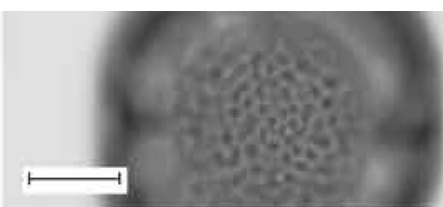

64

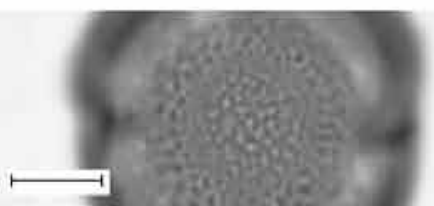

65

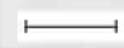

66

67

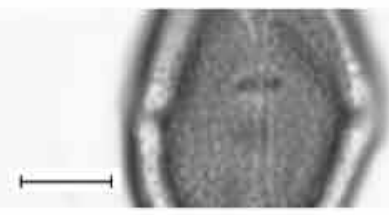

68
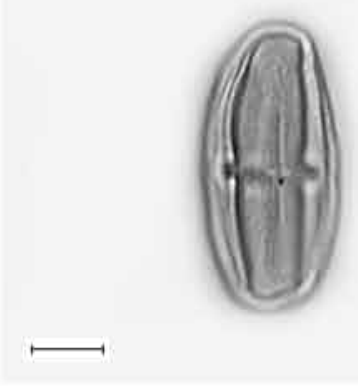

69
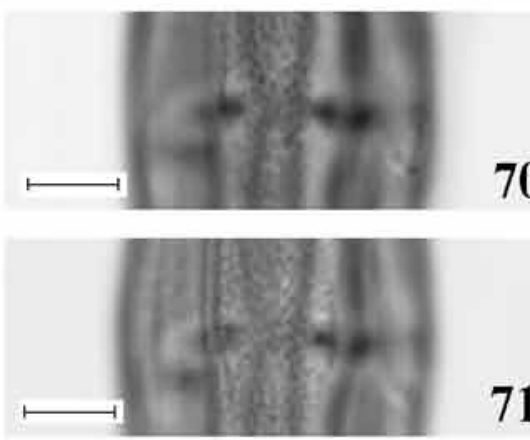

71
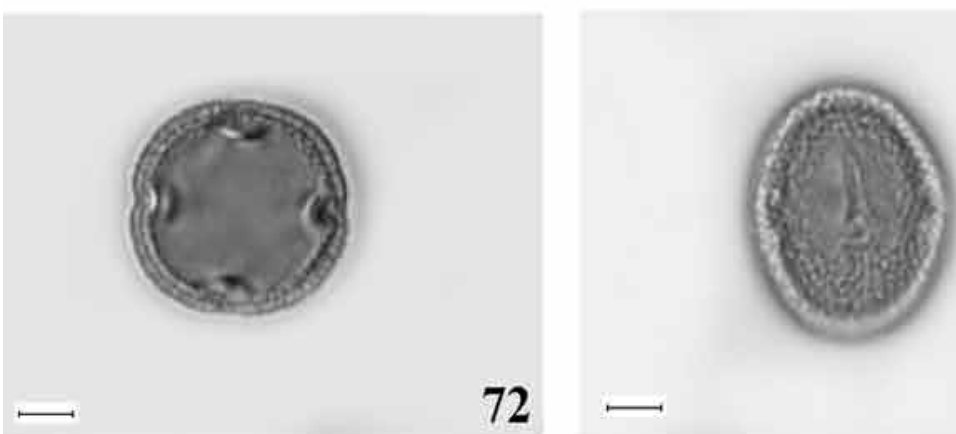

72

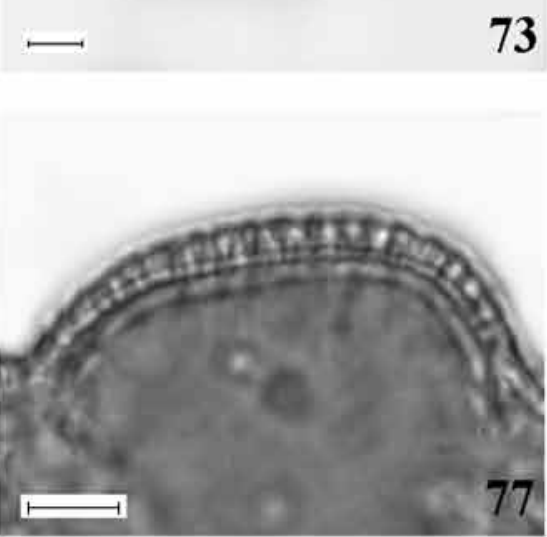

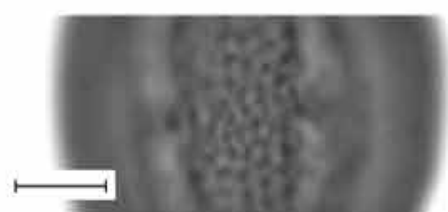

74

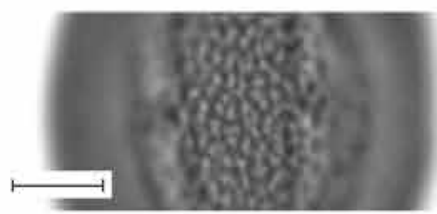

75
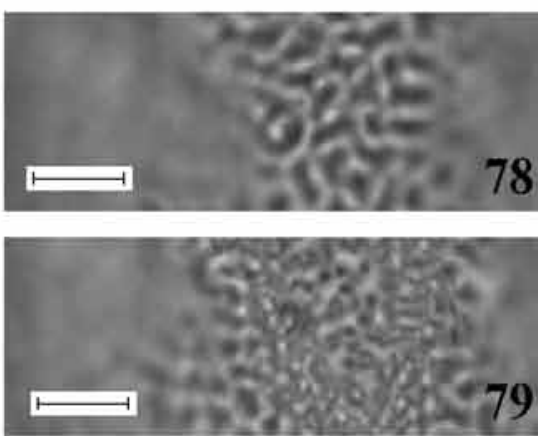

Figuras 63-79. Fotomicrografias dos grãos de pólen de Euphorbiaceae. 63-65. Pera obovata (Klotzsch) Baill. 63. Vista equatorial evidenciando o cólporo. 64-65. Análise de L.O. 66-68. Phyllanthus caroliniensis Walt. 66. Vista equatorial evidenciando o cólporo. 6768. Análise de L.O. 69-71. Phyllanthus niruri L. 69. Vista equatorial evidenciando o cólporo. 70-71. Análise de L.O. 72-75. Phyllanthus tenellus Roxb. 72. Vista polar. 73. Vista equatorial evidenciando o cólporo. 74-75. Análise de L.O. 76-79. Plukenetia serrata (Vell.) L.J. Gillespie. 76. Vista polar. 77. Corte óptico. 78-79. Análise de L.O. Escalas nas figuras 69, $76=10 \mu \mathrm{m}$, demais figuras $=5 \mu \mathrm{m}$.

Figures 63-79. Photomicrographs of pollen grains of the Euphorbiaceae. 63-65. Pera obovata (Klotzsch) Baill. 63. Equatorial view, showing the aperture. 64-65. LO-analysis. 66-68. Phyllanthus caroliniensis Walt. 66. Equatorial view, showing the aperture. 67-68. LOanalysis. 69-71. Phyllanthus niruri L. 69. Equatorial view, showing the aperture. 70-71. LO-analysis. 72-75. Phyllanthus tenellus Roxb. 72. Polar view. 73. Equatorial view, showing the aperture. 74-75. LO-analysis. 76-79. Plukenetia serrata (Vell.) L.J. Gillespie. 76. Polar view. 77. Optical section. 78-79. LO-analysis. Scales in the figures $69,76=10 \mu \mathrm{m}$, remaining figures $=5 \mu \mathrm{m}$. 

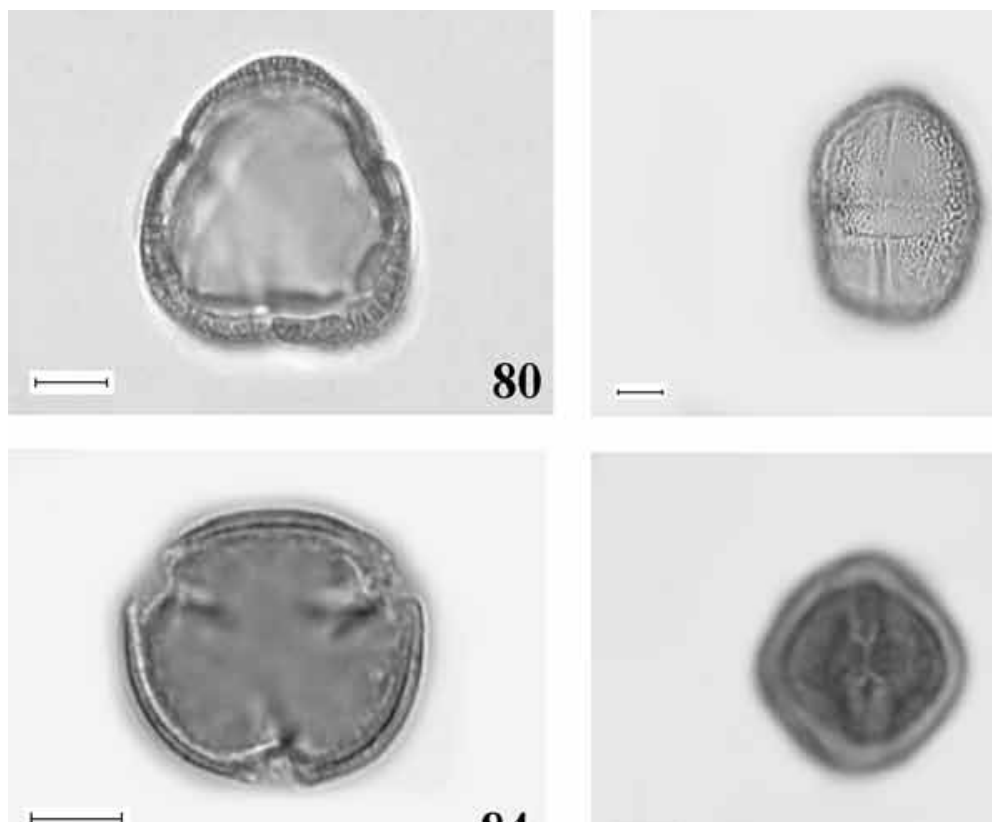

84
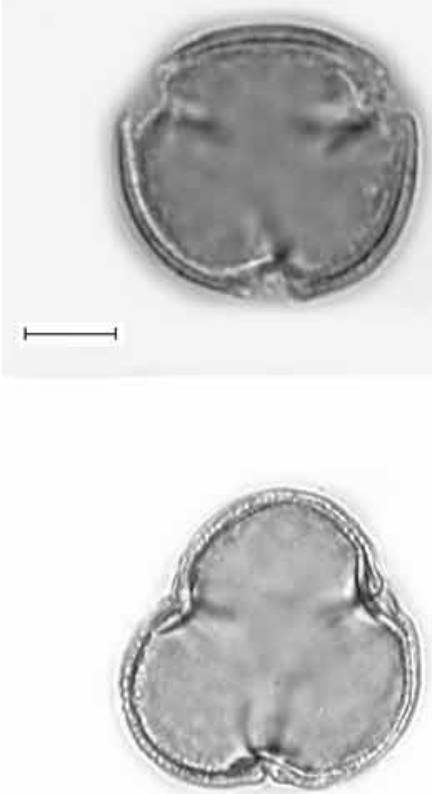

88

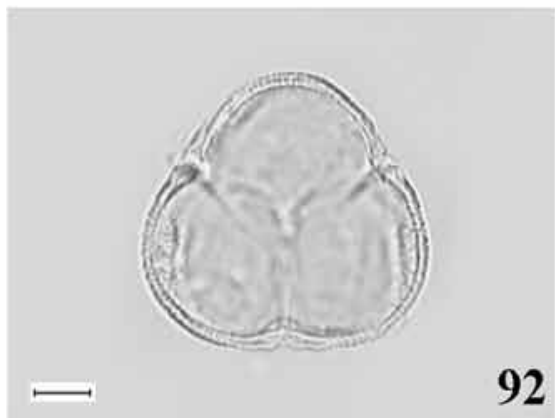

81
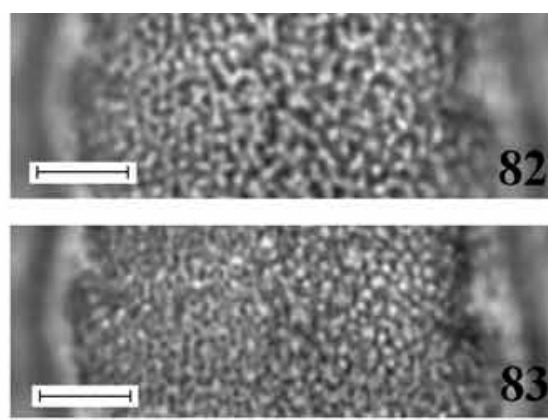

85
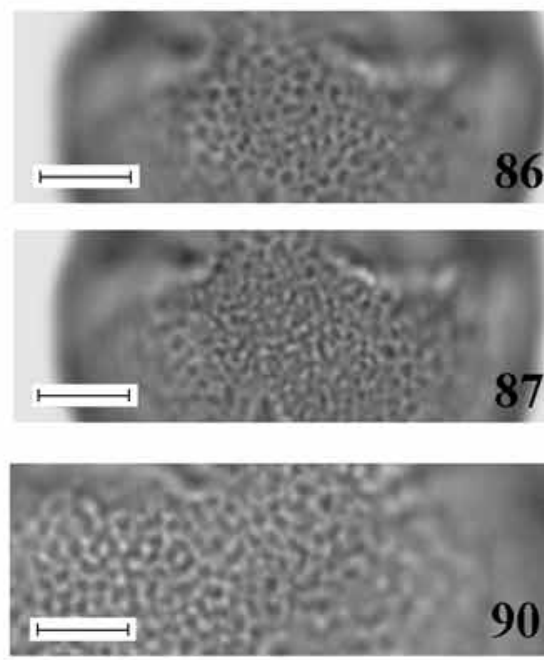

89

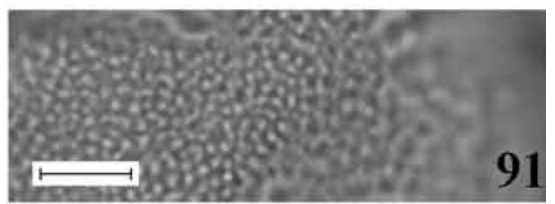

93
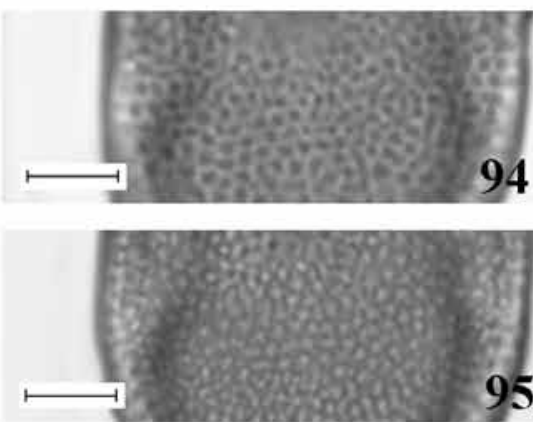

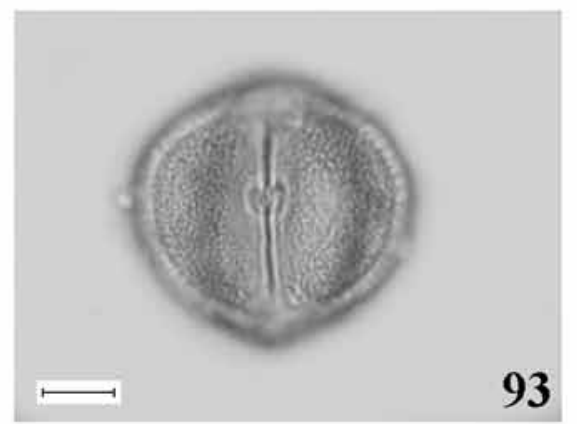

Figuras 80-95. Fotomicrografias dos grãos de pólen de Euphorbiaceae. 80-83. Sapium glandulosum (L.) Morong. 80. Vista polar. 81. Vista equatorial evidenciando o cólporo. 82-83. Análise de L.O. 84-87. Savia dictyocarpa Müll. Arg. 84. Vista polar. 85. Vista equatorial evidenciando o cólporo. 86-87. Análise de L.O. 88-91. Sebastiania klotzschiana (Müll. Arg.) Müll. Arg. 88. Vista polar. 89. Vista equatorial evidenciando o cólporo. 90-91. Análise de L.O. 92-95. Sebastiania serrata (Baill.) Müll. Arg. 92. Vista polar. 93. Vista equatorial evidenciando o cólporo. 94-95. Análise de L.O. Escalas nas figuras 80-81, 88-89, 92-93 = $10 \mu \mathrm{m}$, demais figuras $=5 \mu \mathrm{m}$.

Figures 80-95. Photomicrographs of pollen grains of the Euphorbiaceae. 80-83. Sapium glandulosum (L.) Morong. 80. Polar view. 81. Equatorial view, showing the aperture. 82-83. LO-analysis 84-87. Savia dictyocarpa Müll. Arg. 84. Polar view. 85. Equatorial view, showing of the aperture. 86-87. LO-analysis. 88-91. Sebastiania klotzschiana (Müll. Arg.) Müll. Arg. 88. Polar view. 89. Equatorial view, showing the aperture. 90-91. LO-analysis. 92-95. Sebastiania serrata (Baill.) Müll. Arg. 92. Polar view. 93. Equatorial view, showing the aperture. 94-95. LO- analysis. Scales in the figures 80-81, 88-89, 92-93 $=10 \mu \mathrm{m}$, remaining figures $=5 \mu \mathrm{m}$. 
Sebastiania Spreng.

Grãos de pólen com âmbito subtriangular, prolato-esferoidais a oblato-esferoidais, 3-colporados, cólporos longos, estreitos, com margem; endoaberturas lalongadas; exina microrreticulada; sexina mais espessa que a nexina.

1. Sebastiania klotzschiana (Mül. Arg.) Müll. Arg. Figuras 88-91

Forma: oblato-esferoidal.

Medidas ( $\mu \mathrm{m})$ : O. Handro s.n., SP 43801: $\mathrm{P}$ $=35,27 \pm 0,6 ; \mathrm{E}=39,75 \pm 0,6$; colpo compr. ca. 30,21 , larga. ca. 1,94, endoabertura compr. 5,04, larg ca. 6,24 ; exina ca. 2,81 , sexina ca. 1,35 , teto ca. 1,05 e nexina ca. 0,98 .

Material estudado: 16-XII-1943, O. Handro s.n. (SP43801).

\section{Sebastiania serrata (Baill.) Müll. Arg.}

Figuras 92-95

Forma: oblato-esferoidal a prolato-esferoidal.

Medidas $(\mu \mathrm{m})$ : F.C. Hoehne s.n., SP28301: $\mathrm{P}$ $=28,16 \pm 0,4 ; \mathrm{E}=30,95 \pm 0,5$; colpo compr. ca. 21,92 , larg. ca. 1,76, endoabertura compr. ca. 5,14, larg. ca. 5,60; exina ca. 2,44 , sexina ca. 1,74 , teto ca. 0,79 e nexina ca. 1,04 .

F.C. Hoehne s.n., SP29854: $\mathrm{P}=36,11 ; \mathrm{E}=$ 32,57

Observações: Os materiais da Reserva F.C. Hoehne s.n. (SP29836), M. Kirizawa \& M. Goes 291 (SP), M. Kirizawa 356 (SP), M. Kirizawa 502 (SP), H. Makino s.n. (SP146644), N.A. Rosa \& J.M. Pires 3706 (SP) e M.S. Silvestre 203 (SP) citados por Cordeiro (1989) não foram aqui estudados por apresentarem grãos de pólen amassados. Não foi possível elaborar chave polínica para as duas espécies de Sebastiania aqui estudadas, devido à semelhança morfológica entre seus grãos de pólen tanto qualitativa como quantitativamente.

Material estudado: 30-IX-1931, F.C. Hoehne s.n. (SP28301); 1-IX-1932, F.C. Hoehne s.n. (SP29854).

\section{Agradecimentos}

Os autores agradecem ao Programa Institucional de Bolsas de Iniciação Científica - PIBIC $\mathrm{CNPq}$, pelo auxílio financeiro concedido a Michel Aprigio Pregun e Priscila Gardino Raso.

\section{Literatura citada}

Carneiro-Torres, D.S., Santos, F.A.R. \& Giulietti, A.M. 2002. A tribo Euphorbieae Dumort (Euphorbiaceae) na Chapada Diamantina, Bahia, Brasil: Palinologia e implicações taxonômicas. Polibotánica 13: 83-96.

Carreira, L.M.M., Secco, R.S. \& Barth, O.M. 1996. Pollen morphology of the lianescent species of the genus Croton (Euphorbiaceae). Grana 35: 74-78.

Coelho, L.G. \& Barth, O.M. 2002. Catálogo sistemático de pólen das plantas arbóreas do Brasil Meridional. XXXV: Euphorbiaceae Alchornea, Aparisthmium, Bernardia e Pera. Leandra 17: 35-44.

Cordeiro, I. 1989. Flora Fanerogâmica do Parque Estadual das Fontes do Ipiranga (São Paulo, Brasil). Família 107-Euphorbiaceae. Hoehnea 16: 11-29.

Corrêa-Gomes, J. 1966. Contribuição ao conhecimento do pólen das plantas da Caatinga. Arquivos de Botânica do Estado de São Paulo 4: 89-93.

Cruz-Barros, M.A.V. \& Souza, L.N. 2005. Flora polínica da Reserva do Parque Estadual das Fontes do Ipiranga (São Paulo, Brasil). Família: 10-Piperaceae. Hoehnea 32: 77-85.

Cruz-Barros, M.A.V., Corrêa, A.M.S. \& MakinoWatanabe, H. 2006. Estudo polínico de Aquifoliaceae, Euphorbiaceae, Lecythidaceae, Malvaceae, Phytolaccaceae e Portulacaceae ocorrentes na restinga da Ilha do Cardoso (Cananéia, SP, Brasil). Revista Brasileira de Botânica 29: 145-162.

El-Ghazaly, G.A. 1989. Pollen and orbicule morphology of some Euphorbia species. Grana 28: 243-259.

El-Ghazaly, G.A. \& Chaudhary, R. 1993. Pollen morphology of some species of the genus Euphorbia L. Review of Palaeobotany and Palynology 78:293-319.

Erdtman, G. 1952. Pollen morphology and plant taxonomy - Angiosperms. Almqvist \& Wiksell, Stockholm.

Erdtman, G. 1969. Handbook of palynology. An introduction to the study of pollen grains and spores. Munksgaard, Copenhagen.

Hesse, M., Halbritter, H., Zetter, R., Weber, M., Buchner, R., Frosch-Radivo, A., \& Ulrich, S. 2009. Pollen Terminology. An illustrated handbook. Springer-Verlag, Wien. 
Huang, T.C. 1972. Pollen flora of Taiwan. National Taiwan University, Botany Department Press, Taipei.

Ikuse, M. 1956. Pollen grains of Japan. Hirokawa Publishing Company, Tokyo.

Khan, H.A. 1968. Contributions to the pollen morphology of the Euphorbiaceae. Journal of Palynolynology 4: 21-35.

Lima, L.R., Cruz-Barros, M.A.V., Pirani, J.R. \& Corrêa, A.M.S. 2007. Pollen morphology of Croton sect. Lamprocroton (Müll. Arg.) Pax (Euphorbiaceae) and its taxonomic implications. Nordic Journal of Botany 25: 206-216.

Lozano-Garcia, S. 1979. Atlas de pollen de San Luis Posoli, México. Pollen et Spores 21: 287336

Meewis, B. \& Punt, W. 1983. Pollen morphology and taxonomy of the subgenus Kirganelia (Jussieu) Webster (Genus Phyllanthus, Euphorbiaceae) from Africa. Review of Palaeobotany and Palynology 39: 131-160.

Melhem, T.S., Giulietti, A.M., Forero, E., Barroso, G.M., Silvestre, M.S.F., Jung, S.L., Makino, H., Melo, M.M.R.F., Chiea, S.C., Wanderley, M.G.L., Kirizawa, M. \& Muniz, C. 1981. Planejamento para elaboração da "Flora Fanerogâmica da Reserva do Parque Estadual das Fontes do Ipiranga (São Paulo, Brasil)". Hoehnea 9: 63-74.

Melhem, T.S., Makino, H., Silvestre, M.S.F., Cruz, M.A.V. \& Jung-Mendaçolli, S. 1984. Planejamento para elaboração da "Flora Polínica da Reserva do Parque Estadual das Fontes do Ipiranga (São Paulo, Brasil)". Hoehnea 11: 1-7.

Melhem, T.S., Cruz-Barros, M.A.V., Corrêa, A.M.S., Makino-Watanabe, H., SilvestreCapelato, M.S.F. \& Esteves, V.L.G. 2003. Variabilidade polínica em plantas de Campos do Jordão (São Paulo, Brasil). Boletim do Instituto de Botânica 16: 1-104.

Nakajima, J.N., Esteves, R.L., GonçalvesEsteves, V., Magenta, M.A.G., Bianchini, R.S., Pruski, J.F. \& Hind, D.J.N. 2001. Flora Fanerogâmica da Reserva do Parque Estadual das Fontes do Ipiranga (São Paulo, Brasil). 159-Asteraceae. Hoehnea 28: 111-181.
Nowicke, J.W. 1994. A Palynological study of Crotonoideae (Euphorbiaceae). Annals of the Missouri Botanical Garden 81: 245-269.

Nowicke, J.W. Takahashi, M. \& Webster, G.L. 1998. Pollen morphology, exine structure and systematics of Acalyphoideae (Euphorbiaceae), Part. 1. Tribes Clutieae (Clutia), Pogonophoreae (Pogonophora), Chaetocapeae (Chaetocarpus, Trigonopleura), Pereae (Pera), Cheiloseae (Cheilosa, Neoscortechinia), Eismantheae pro parte (Erismanthus, Moultonianthus), Dicoelieae (Dicoelia), Galearieae (Galearia, Microdesmis, Panda) and Ampereae (Amperea, Monotaxis). Review of Paleobotany and Palynology 102: 115-152.

Oliveira, P.P. \& Santos, F.A.R. 2000. Morfologia polínica do gênero Croton L. (Euphorbiaceae) dos inselbergs da região de Milagres (BahiaBrasil). Revista Universidade de GuarulhosGeociências (número especial) 5: 212-215.

Perveen, A. \& Qaiser, M. 2005. Pollen flora of Pakistan- XLVII. Euphorbiaceae. Pakistan Journal of Botany 37: 785-796.

Punt, W. 1962. Pollen morphology of the Euphorbiaceae with special reference to taxonomy. Wentia 7: 1-116.

Punt, W. 1987. Convergence in some interesting pollen types of Phyllanthus (Euphorbiaceae). Canadian Journal of Botany 64: 3127-3129.

Roubik, D.W. \& Moreno P., J.E. 1991. Pollen and spores of Barro Colorado Island. Monograph in Systematic Botany 36: 1-268.

Sagun, V.G. \& van der Ham, R.W.J.M. 2003. Pollen morphology of the Flueggeinae (Euphorbiaceae, Phyllanthoideae). Grana 42: 193-219.

Salgado-Labouriau, M.L. 1967. Pollen grains of plants of the "Cerrado". XIX - Euphorbiaceae. Anais da Academia Brasileira de Ciências 39: 471-490.

Salgado-Labouriau, M.L. 1973. Contribuição à palinologia dos cerrados. Academia Brasileira de Ciências, Rio de Janeiro.

Santiago, L.J.M., Louro, R.P. \& Barth, O.M. 2004. The pollen morphplogy of Phyllanthus (Euphorbiaceae) section Choretropsis. Botanical Journal of the Linnean Society 144: 243-250. 
Secco, R. 1997. Revisão taxonômica das espécies neotropicais da tribo Alchorneae (Hurusawa) Hutchinson (Euphorbiasceae). Tese de Doutorado, Universidade de São Paulo, São Paulo.

Silva, E.L. 2008. Estudo polínico das espécies de Phyllanthus L. subgen. Conami (Aubl.) G.L. Webster e subg. Phyllanthus no Brasil. Dissertação de Mestrado, Instituto de Botânica, São Paulo.
Takahashi, M., Nowicke, J,W. \& Webster, G.L. 1995. A note on remarkable exines in Acalyphoideae (Euphorbiaceae). Grana 34: 282-290.

Webster, G.L. \& Burch, D. 1967. Flora of Panama. Part VI. Family 97. Euphorbiaceae. Annals of the Missouri Botanical Garden 54: 211-350. 